\begin{tabular}{|c|l|}
\hline Title & $\begin{array}{l}\text { Development of the Nonlinear Bond Stress Slip Model of Fiber Reinforced Plastics Sheet-Concrete Interfaces with a } \\
\text { Simple Method }\end{array}$ \\
\hline Author(s) & Dai, Jianguo; Ueda, Tamon; Sato, Y asuhiko \\
\hline Citation & $\begin{array}{l}\text { Journal of Composites for Construction, 9(1), 52-62 } \\
\text { https://doi.org/10.1061/A SCE)1090-0268(2005)9:1(52) }\end{array}$ \\
\hline Issue Date & 2005 \\
\hline Doc URL & http://hdl.handle.net/2115/5921 \\
\hline Type & article (author version) \\
\hline File Information & JCc9-1.pdf \\
\hline
\end{tabular}

Instructions for use 


\title{
Development of the Nonlinear Bond Stress-Slip Model of Fiber Reinforced Plastics Sheet-concrete Interfaces with a Simple Method
}

\author{
By Jianguo Dai ${ }^{1}$, Tamon Ueda ${ }^{2}$ and Yasuhiko Sato ${ }^{3}$
}

\begin{abstract}
In this paper, a new analytical method for defining the nonlinear bond stress-slip models of Fiber Reinforced Plastics (FRP) sheet-concrete interfaces through pullout bond test is proposed. With this method, it is not necessary to attach many strain gages on the FRP sheets for obtaining the strain distributions in FRP as well as the local bond stresses and slips. Instead, the local interfacial bond stress-slip models can be simply derived from the relationships between the pullout forces and loaded end slips. Based on a series of pullout tests, the bond stress-slip models of FRP sheet-concrete interfaces, in which different FRP stiffness, FRP materials (Carbon FRP, Aramid FRP, Glass FRP), and adhesives are used, have been derived. Only two parameters, the interfacial fracture energy and interfacial ductility index, which can take into account the effects of all interfacial components, are necessary in these models. Comparisons between analytical results and experimental ones show good accordance, indicating the reliability of the proposed method and the proposed bond stress-slip models.
\end{abstract}

Keywords: Fiber Reinforced Plastics, Concrete, Adhesives, Interface shear, Bond Stress, Slip, Fracture Mechanics

\section{INTRODUCTION}

Bonding FRP sheets externally to strengthen the existing deficient reinforced concrete (RC) structures has become a popular technology in the past decade. With the rapid development of this new technology, many issues related to the structural performances of FRP strengthened RC elements have been studied. Among them the study on the interfacial bond between the externally bonded FRP sheets and concrete may be the most fundamental one because it plays a key role on the composite performances and the durability of RC structures after being strengthened. In order

\footnotetext{
1 Post-doctoral Fellow, Division of Structural and Geotechnical Engineering, Hokkaido University, Sapporo, 060-8628, Japan, Email: daijg@eng.hokudai.ac.jp

${ }^{2}$ Assoc. Prof., Division of Structural and Geotechnical Engineering, Hokkaido University, Sapporo, 060-8628, Japan, Email: ueda@eng.hokudai.ac.jp

${ }^{3}$ Research Associate, Division of Structural and Geotechnical Engineering, Hokkaido University, Sapporo, 060-8628, Japan, Email: ysato@eng.hokudai.ac.jp
} 
to evaluate the interfacial bond mechanisms quantitatively and carry out numerical simulation for FRP sheets strengthened RC structures, defining an accurate bond stress-slip ( $\tau \sim \mathrm{s})$ relationship has become a main task among the bond issues studied in the past. The conventional way of finding a $\tau \sim \mathrm{s}$ relationship for FRP sheets bonded to concrete depends on the strain distributions of FRP and local bond stresses measured by many strain gages mounted on FRP sheets. However, it is difficult for us to apply this way for FRP sheet-concrete interfaces because of the difficulty in arranging many gages in a short effective load transfer length. The highly scatter nature of local $\tau \sim \mathrm{s}$ relationships is another difficulty we face. Particularly, local bending of FRP sheets whose bending stiffness is small introduces significant bending strains in FRP and coarse aggregates in a concrete surface layer are causes of the scatter. Therefore, the objectives of this study are as follows:

1. To develop a simple but rigorous analytical way to derive the local $\tau \sim \mathrm{s}$ relationship based on the relationship between the pullout loads and slips at the loaded end in a pullout test rather than the observations on the strain distributions of FRP sheets and local bond stress behaviors.

2. To propose the nonlinear interfacial $\tau \sim \mathrm{s}$ relationships for FRP sheet-concrete interfaces based on the experimental studies and the proposed method, in which the effects of all interfacial materials including concrete, FRP, and adhesive layer can be taken into account.

\section{LITERATURE REVIEW}

A fairly large amount of bond tests for the FRP sheet-concrete interfaces under shear have been carried out in the past. Test methods include single lap pullout test method (Chajes et al. 1996, Täljsten et al. 1997, Bizindavyi et al. 1999), double lap pull-out bond tests (Nakaba et al. 2001, Yoshizawa et al. 2000, Sato et al. 2000, Brosens and Gemert 1997, Sato et al. 1997), shear bending tests (Leung 2001, Lorenzis et al. 2001), and bond tests for the critical strain energy release rate (Karbhari and Engineer 1996, Fukuzawa et al. 1997). Through those experimental studies, the bond mechanisms of FRP sheet-concrete interfaces have been clarified in the following aspects:

(a) Bond strength: The bond strength of FRP sheet-concrete interfaces has been studied most intensively. The FRP sheet-concrete interface fails mostly at a thin layer beneath the concrete surface. As a result, the concrete surface condition and strength are critical factors affecting the interfacial bond strength. The concrete surface treatment methods have been studied experimentally (Chajes et al. 1996) and quantified in details by using 3D profile method to evaluate the concrete surface roughness index (Mitsui et al. 2000). At present sandblasting is the most common 
surface treating method that is being adopted in many researches and accepted in practical sites. Chajes et al. (1996), Horiguchi (1997) and Sato et al. (2000) studied the effects of concrete strength $f_{c}^{\prime}$ and concluded that the average interface bond strengths, which are the ultimate pull-out forces divided by bond areas between FRP sheets and concrete, are linearly proportional to $\mathrm{f}_{\mathrm{c}}{ }^{\prime 1 / 2}, \mathrm{f}_{\mathrm{c}}{ }^{2 / 3}$, and $\mathrm{f}_{\mathrm{c}}{ }^{1 / 5}$ respectively.

Besides the concrete property, the FRP and adhesive properties affect the interface bond strength as well. In general, using higher FRP stiffness (Brosens and Gemert 1997, Bizindavyi et al. 1999, Yoshizawa et al. 2000, Lorenzis et al. 2001, Nakaba et al. 2001) and softer adhesives (Nishida et al. 1999, Dai et al. 2002) can increase the average bond strength. Chen and Teng (2001) reviewed the current models for predicting the bond strength of FRP sheet-concrete interface with different bond lengths. They classified all the models into three categories: empirical models based directly on the regression of test data, model based on fracture mechanics, and models meant directly for design purpose, which generally make use of some simple assumptions.

(b) Interfacial fracture energy: The interfacial fracture energy $\mathrm{G}_{\mathrm{f}}$, which is the area underneath the interfacial bond stress-slip curve, is an important parameter for the bond characteristics. Based on different types of interfacial bond stress-slip relationships, Yuan et al. (2001) proved that the maximum interfacial bond force can be expressed as a function of the $G_{f}$ and FRP stiffness (elastic modulus xthickness). Due to the clear physical meaning of the $G_{f}$, it is very useful to apply it in numerical analysis for deriving bond strength and anchorage length models as well as for clarifying the debonding failure mechanisms of FRP sheet-concrete interfaces in more comprehensive ways (Yin and Wu 1999, Wu and Yin 2002). The $G_{f}$ is usually expressed as a function of concrete tensile strength (Brosens and Gemert 1999). However, the effects of adhesive layer on the $\mathrm{G}_{\mathrm{f}}$ have been hardly reported.

(c) Effective bond length: There exists an active bonding zone named as the effective bond length $L_{e}$, along which most of the interfacial load is transferred between FRP sheets and concrete. When the bond length of FRP sheet-concrete interfaces exceeds the $L_{e}$, the bond strength will not increase significantly any longer. With a few exceptions (Maeda et al. 1997), it was reported that the effective bond length increases with the stiffness of FRP sheets. Nevertheless, due to the different definitions given by different researchers and the different materials used in their tests, the effective bond length was reported in a fairly big range, such as $45 \mathrm{~mm}$ (Sato et al. 1997), $75 \mathrm{~mm}$ (Miller and Nanni 1999), 93 mm (Lorenzis et al. 2001), 100 mm (Ueda et al. 1999), 63.5 134.5 mm (Nakaba et al. 2001), and $275 \mathrm{~mm}$ (Brosens and Gemert 1997). Yuan et al. (2001) gave a theoretical expression for the effective bond length (defined as the bond length undertaking the $97 \%$ of whole interfacial load) based on the assumed 
interfacial fracture energy and interfacial bilinear $\tau \sim s$ relationship.

(d) Bond stress slip ( $\tau \sim s$ ) relationship: As the most fundamental constitutive laws that characterize the bond of FRP sheet-concrete interfaces, several empirical $\tau \sim \mathrm{s}$ relationships have been proposed as follows:

1. Elasto-plastic model by Sato et al. (1997) and Lorenzis et al. (2001);

2. Bilinear model based on the interfacial fracture energy $G_{f}$ (Yoshizawa et al. 2000).

3. Model based on Popovic's expression by Nakaba et al. (2001).

4. Shear softening model by Sato et al. (2000).

Above-mentioned models configure the shapes of the $\tau \sim$ s relationships in different ways (see the comparison in Fig. 1). The concrete strength is assumed as a constant value 35MPa for all models shown in Fig. 1 for the comparing purpose. Although the elastic modulus of the adhesives in those studies for model developing are similar, it can be seen that fairly big differences exist among those models. Those differences may be due to the dissimilar interfacial material properties (e.g. FRP stiffness) or the bonding skills (the deviations of concrete surface conditions or the adhesive’s thickness) applied in different studies. Besides that, the fairly big scattering among the experimentally observed bond stress-slip relationships at different interfacial locations (to be shown in the next section) may be another factor, which affects the decisions on the shapes of the $\tau \sim \mathrm{s}$ relationships and the calibration of the needed empirical parameters. The FRP sheet-concrete interface is composed of FRP sheets, adhesive layer, and concrete, each one of which affects the interfacial mechanical properties. To consider these effects, calibrating many empirical parameters in an unknown $\tau \sim$ s relationship without consideration of their corresponding physical meanings is a very complex task. Up to now it can be said that the interfacial bond mechanisms between FRP sheets and concrete have been clarified qualitatively in some extent. However, in order to carry out accurate quantitative simulation for the FRP sheet-concrete interfaces, the way of determining a $\tau \sim$ s relationship should be further improved.

\section{EXPERIMENTAL OUTLINE}

A single-lap pullout test setup (see Fig. 2) including: a thick steel basement fixed to strong floor through four prestressed high strength bolts, a steel box connected to the steel basement through two lines of steel bolts, concrete block with the size of $400 \times 200 \times 400 \mathrm{~mm}$, FRP sheets externally bonded to the concrete block, and connectors between the end of the FRP sheets and actuator, was applied in the study. In the concrete block, four plastic pipes 
with diameter of $30 \mathrm{~mm}$ were pre-set vertically, so that the concrete block could be fixed on the steel box symmetrically and stably through four steel bolts. The connectors between the FRP sheets and the actuator contain two directional hinges, ensuring that the end of the FRP sheets can be rotated freely to avoid bending or torsion effect.

The width of FRP sheets is $100 \mathrm{~mm}$. In order to exert uniform tensile forces to the FRP sheets, two steel plates were adhered to both sides of FRP sheets. Two additional bolts were used to enhance the bond between FRP sheets and steel plates to avoid the bond failure in FRP sheet-steel plate interfaces ahead of that in FRP sheet-concrete interfaces. The attached area of FRP sheets to steel plates is $100 \times 100 \mathrm{~mm}$. In order to avoid local damage of the concrete block, an un-bonded length $(50 \mathrm{~mm})$ was set by using vinylon tape to separate the concrete surface from the FRP sheets. It is very important to keep the midline of the FRP sheets vertically, on which the center of actuator is located. To achieve this purpose, the location of the concrete block was carefully adjusted on the steel box.

During the pullout test procedures, the displacement control loading system was applied. LVDT transducers were set at both the loaded and free ends of the bond area to obtain the relative slips between the FRP sheets and concrete. The load cell and the transducers were connected to the data logger then the load and slip signals were recorded simultaneously by a computer.

Four types of adhesives (including one type of primer) and three types of FRP sheets were applied in the study. The mechanical properties of adhesives and FRP sheets and the information of manufacturers are shown in Table 1 and Table 2 respectively. Due to the obvious non-linearity when the adhesive becomes softer (see the tensile stress-strain relationships of adhesives in Fig. 3), the initial elastic modulus adhesives is defined as the average secant modulus while the strain lies between 0.0005 and 0.0025 (JIS 1995). Both the elasticity modulus and thickness of bond layer affect the interfacial bond properties (Lee et al. 1999, Tripi et al. 2000, Dai et al. 2002). Therefore, the property of bond layer can be quantified using its shear stiffness (shear modulus/thickness) as follows:

$$
\frac{G_{a}}{t_{a}}=\frac{G_{p} \cdot G_{a d}}{G_{p} t_{a d}+G_{a d} t_{p}}, \quad G_{p}=\frac{E_{p}}{2\left(1+\gamma_{p}\right)}, \quad G_{a d}=\frac{E_{a d}}{2\left(1+\gamma_{a d}\right)}
$$

where: $G_{a}$ is the shear modulus of adhesive layer; $t_{a}$ is the thickness of adhesive layer; $E_{P}, E_{a d} ; t_{p}, t_{a d}$ and $Y_{p}, Y_{a d}$ are the elasticity modulus, thickness and Poisson ratio of primer and adhesive layer respectively. As indicated in Eq.1, the shear stiffness of bond layer is that of a combined layer of primer and adhesive.

To obtain the accurate geometrical information about the adhesive layer, the FRP sheets attached with failed concrete 
were processed after the pullout tests. Then the thickness of every bonding layer (primer and adhesive layer) was measured under a microscope (see Fig. 4). After that the shear stiffness of adhesives could be calculated through Eq.1 (see the values in Table 3). Ready-mixed concrete with the tested compressive strength of 35 MPa was prepared in order to keep a same strength for all specimens. Moreover, in order to observe the whole peeling-off procedures, the bond length of $330 \mathrm{~mm}$ was applied.

Wet-lay-up bonding system was applied in the study. However, to avoid the decreasing of the tensile strength of FRP sheets induced by the resin matrix with low elasticity modulus (e.g. CN-100), the resins used in FRP layers and the adhesive layers were different (see Fig. 4 ). Adhesive FR-E3P, which is commercially used as the resin matrix and the bonding adhesive of carbon fiber sheets, was applied as the resin matrix of FRP in all specimens. The primer FP-NS was used in the bonding procedures of all specimens. After the adhesive bond layer was cured for 24 hours, resin FR-E3P was used to form FRP layers as shown in Fig. 4. The details of the specimens can be found in Table 3.

\section{ANALYSIS ON TEST RESULTS}

\section{Description of the Methodology}

Generally, in order to obtain the local bond stress-slip relationships of FRP sheet-concrete interfaces from the direct pullout bond test, many strain gages should be attached with a small interval (10 mm 20 mm) on the surfaces of FRP sheets (JCI TC952 1998). As a result, the strain distribution of FRP sheets along the interfaces corresponding to every step load can be obtained. Fig. 5 shows the sketch of a single lap pullout bond test setup. Supposed that the interval of gages is a constant value $\Delta x$, the local bond stress can be obtained using the following expression:

$$
\tau_{i}=\frac{E_{f} t_{f}\left(\varepsilon_{i}-\varepsilon_{i-1}\right)}{\Delta x}
$$

where $\tau_{\mathrm{i}}$ is the average interfacial bond stress in the section $\mathrm{i} ; \varepsilon_{\mathrm{i}}$ and $\varepsilon_{\mathrm{i}-1}$ are the strain values of the $\mathrm{i}$ th and $\mathrm{i}-1$ th gages arranged on a FRP sheets respectively; $E_{f}$ and $t_{f}$ are the elastic modulus and thickness of the FRP sheets respectively.

The local slip is caused by the strain difference between FRP sheets and concrete. The strain of concrete can be neglected and the free end slip can be regarded approximately as zero in the case of using a long bond length. So the local slip can be expressed as: 


$$
S_{i}=\frac{\Delta x}{2}\left(\varepsilon_{0}+2 \sum_{j=1}^{i-1} \varepsilon_{j}+\varepsilon_{i}\right)
$$

where $s_{i}$ is the local slip between FRP sheets and concrete at the section $i ; \varepsilon_{0}$ is the strain of FRP sheets at the free end of bond area. $\varepsilon_{\mathrm{j}(\mathrm{j}=1, \mathrm{i})}$ is the strain value of the $\mathrm{j}$ th gage arranged on the FRP sheets.

Fig. 6 is a paradigm of obtained strain distributions of specimen CR1L1 (with adhesive FR-E3P and one layer of FRP sheet) in the authors' previous study (Dai et al. 2002). Upon Eq.2 and Eq.3, the local $\tau \sim s$ relationships at different locations from the loaded point in a pullout test can be derived as shown in Fig. 7. Obviously, fairly big irregular differences among those $\tau \sim \mathrm{S}$ relationships are observed at different interfacial locations. The similar experimental observations can be found in other literatures (Yoshizawa et al. 2000, Nakaba et al. 2001, Sato et al. 2000). This fairly big variation probably is the main reason why different shapes of bond stress-slip relationships were proposed or why researchers prefer a simplified bilinear bond stress-slip model even though numerous of pullout bond tests for FRP sheets-concrete interfaces have indicated that more reasonable configurations are needed. All the factors such as the distribution of fine and coarse aggregates along the concrete surface, the concrete volume attached to FRP sheets after the initial damage of concrete, and the local bending of FRP sheets or the local mixed-mode failure of concrete can contribute to the final scattering. It is not convincing to pick up one of these local $\tau \sim$ s relationships to represent the overall one. In order to clarify the local interfacial bond mechanisms exactly, simulating the bonding among coarse aggregates, mortars, adhesives and FRP sheets at a microscopic level may be a more precise way. However, it is much more difficult to get the microscopic-level constitutive model of the interface. The authors (Dai and Ueda 2003) proposed a back calculation method, which tried to minimize the differences between the experimentally observed strain distributions and the analytical ones, to calibrate the unknown parameters needed for an assumed bond-stress slip curve optimally. Nevertheless, the analytical results on the unknown parameters rely much on the selected shape of the $\tau \sim$ s relationships. In the following part, an improved method on how to obtain interfacial $\tau \sim \mathrm{S}$ relationships without the necessity to record the strain distributions of FRP sheets is to be discussed.

At any location of an FRP sheet-concrete bond interface under the boundary condition of zero free end slip, which can be approximately attained using a longer bond length, there exists a unique $\tau \sim \mathrm{s}$ relationship and a unique relationship between the strain of FRP sheets and interfacial slip (Shima et al. 1987). The latter can be expressed as follows: 


$$
\varepsilon=f(s)
$$

where $\varepsilon$ is the strain of FRP sheets at any location; $\mathrm{S}$ is the corresponding slip at that location.

A first order differential calculus of $\varepsilon$ to $\mathrm{x}$ yields the following equation:

$$
\frac{d \varepsilon}{d x}=\frac{d f(s)}{d s} \cdot \frac{d s}{d x}=\frac{d f(s)}{d s} \cdot \varepsilon=\frac{d f(s)}{d s} \cdot f(s)
$$

Therefore, for FRP sheet-concrete interfaces, the interfacial bond stress can be expressed as:

$$
\tau=E_{f} t_{f} \cdot \frac{d \varepsilon}{d x}=E_{f} t_{f} \cdot \frac{d f(s)}{d s} \cdot f(s)
$$

where $E_{f} t_{f}$ is the stiffness of FRP sheets (elastic modulus $\times$ thickness).

It can be seen from Eq.4 to Eq.6 that the bond stress-slip relationship can be determined if the relationship between local strain of FRP sheets and local slip is defined. During the pullout test, the pullout forces and the slips at the loaded end can be measured accurately through load cell and displacement transducer. As a result, the relationship between the strains of FRP sheets and the slips at the loaded end, in other word, the function of $\mathrm{f}(\mathrm{s})$ can be obtained directly from the simple pullout tests.

Fig. 8.a to Fig. 8.e are the experimentally observed relationships between the strains of FRP sheets and the interfacial slips at the loaded ends of FRP sheet-concrete interfaces, which include cases of different FRP stiffnesses, different adhesive types and different types of FRP materials. It is found that the exponential expression (see Eq.7) can fit the experimental results very well (the values of correlative factors $\mathrm{R}^{2}$ between the strains in FRP sheets and the slips at loaded ends lie between 0.975 and 0.997 for all specimens as shown in Table 3).

$$
\varepsilon=f(s)=A(1-\exp (-B s))
$$

where A and B are experimental parameters (the values for each specimen are given in Table 3).

Therefore:

$$
d f(s) / d s=A B \exp (-B s)
$$

Once Eq.7 and Eq.8 are substituted into Eq.6, the bond stress-slip relationship can be obtained as follows:

$$
\tau=A^{2} B E_{f} t_{f} \exp (-B s)(1-\exp (-B s))
$$

The interfacial fracture energy $\mathrm{G}_{\mathrm{f}}$ is defined as: 


$$
G_{f}=\int_{0}^{\infty} \tau d s
$$

By substituting Eq.9 into Eq.10, the following equations can be obtained:

$$
G_{f}=\frac{1}{2} A^{2} E_{f} t_{f}
$$

Then the following expression for A is obtained:

$$
A=\sqrt{\frac{2 G_{f}}{E_{f} t_{f}}}
$$

For FRP sheets bonded to concrete under pullout load, the theoretical maximum interfacial pullout force can be expressed as follows:

$$
P_{\max }=b_{f} E_{f} t_{f} \varepsilon_{\max }=b_{f} E_{f} t_{f} \lim _{s \rightarrow \infty} A(1-\exp (-B s))=b_{f} E_{f} t_{f} A
$$

where $b_{f}$ is the bond width of FRP sheets with concrete; and $\varepsilon_{\max }$ is the maximum strain of FRP sheets corresponding to the maximum pullout force.

The comparisons between the calculated maximum pullout forces based on the regressed A (see Eq.13) and the experimental ones are shown in Fig. 9. It can be seen that good agreement can be reached. The agreement implies that the theoretical maximum interfacial pullout force predicted based on the assumption of zero end slip boundary condition can be reached through using the bond length of 330mm in the experiment With the substitution of Eq.12, Eq.13 can become:

$$
P_{\max }=b_{f} E_{f} t_{f} A=b_{f} \sqrt{2 E_{f} t_{f} G_{f}}
$$

Based on energy method or force equilibrium method, Eq.14 was derived by many researchers (Täljsten et al. 1997, Yuan et al. 2001) and now is applied widely in predicting the ultimate bond forces of FRP sheet-concrete interfaces. And also, through experimental study, the authors found that Eq.14 is applicable for all types of FRP materials regardless of the differences in their elastic modulus (Dai et al. 2002, Dai and Ueda 2003).

The shear stress flows can spread to the concrete in the vicinity of both sides of FRP sheets if the FRP sheets are attached to concrete whose width is wider than theirs. That makes the effective interfacial contact areas wider than the real ones. The authors observed the effects of bond width of FRP sheets (from $1 \mathrm{~cm}$ to $20 \mathrm{~cm}$ ) on the average bond strength in the previous studies (Sato et al. 2000). The experimentally obtained bond force per unit width of 
FRP sheets $\left(P_{\text {max }} / b_{f}\right)$ is generally high when the width of FRP sheets used in the tests is narrow. When the bond width exceeds $10 \mathrm{~cm}$, the value of $P_{\text {max }} / b_{f}$ becomes almost constant. An additional width $2 \Delta b_{f}\left(\Delta b_{f}\right.$ is taken as 3.7 mm) can be added to the original bond width $b_{f}$ for calculating the interfacial bond strength and quantifying the bond width's effects ( Sato et al., 2000). Here a same $2 \Delta b_{f}$ is introduced into Eq.14. Through that the back-calculated $G_{f}$ from obtained $\mathrm{P}_{\max }$ will not depend on the FRP sheet' width used in the test. Therefore, Eq.14 can be modified as follows:

$$
P_{\max }=\left(b_{f}+2 \Delta b_{f}\right) \sqrt{2 E_{f} t_{f} G_{f}}
$$

From Eq.15 it can be known that the interfacial load carrying capacity is determined by the interfacial fracture energy and FRP stiffness. Increasing both the fracture energy and FRP stiffness (by increasing either the amount or elastic modulus of FRP materials) can improve the ultimate interfacial load carrying capacity. Similarly, the usable strain (strength) of FRP sheets is determined by the interfacial fracture energy and the FRP stiffness as well (see Eq.12). High interfacial fracture energy can increase the usable strength or strength efficiency of FRP sheets; however, high FRP stiffness cannot. Therefore, in order to utilize the FRP materials more efficiently in consideration of their decreasing but still higher costs, besides ensuring the concrete surface quality, more effects should be put on to find optimum adhesive layer to improve the interfacial fracture energy.

\section{Discussion on the Interfacial Fracture Energy and the Bond Stress-slip Relationships}

With Eq.9 and Eq.12, the interfacial $\tau \sim$ s relationship can be rewritten as:

$$
\tau=2 B G_{f}(\exp (-B s)-\exp (-2 B s))
$$

in which only two parameters, the interfacial fracture energy $G_{f}$ and another interfacial material constant $B$ are needed for defining the bond stress-slip relationship.

Let,

$$
d \tau / d s=-2 B^{2} G_{f}(\exp (-B s)-2 \exp (-2 B s))=0
$$

The slip $\mathrm{s}_{\max }$ corresponding to the maximum bond stress $\tau_{\max }$, at which $\mathrm{d} \tau / \mathrm{ds}=0$, can be determined as follows:

$$
S_{\max }=\ln 2 / B=0.693 / B
$$

By substituting Eq.18 into Eq.16, the maximum bond stress $\tau_{\max }$ can be obtained as well:

$$
\tau_{\max }=0.5 B G_{f}
$$

For every specimen in the present study, the material constant B and the interfacial fracture energy $G_{f}$ can be 
obtained according to the processes proposed in the previous section (see the results in Table 3). Then the values of $\tau_{\max }$ and $\mathbf{S}_{\max }$ are calculated and shown in Table 3. For the normal adhesive (FRP-E3P), Nakaba et al. (2001) observed experimentally that the values of $\mathrm{s}_{\max }$ lie between 0.052 and $0.087 \mathrm{~mm}$, with which the analytical results (0.053 0.077 mm) based on the present method show good agreement. Based on the above-mentioned process, all the found bond stress-slip relationships derived from pullout tests are shown in Fig. 10. When the FRP fracture failure happens, the obtained $\tau \sim \mathrm{s}$ relationships are excluded because the peeling off process is interrupted and the interfacial fracture energy cannot be calculated correctly. To get a unified $\tau \sim s$ model in consideration of the effects of all interfacial materials, the following paragraphs give results of regression analysis for the two important parameters $\mathrm{G}_{\mathrm{f}}$ and $\mathrm{B}$ based on experimental results.

The interfacial fracture energy $G_{f}$ is affected by the properties of concrete, adhesives and the FRP stiffness. It has been mentioned that, in the case of long bond lengths, $G_{f}$ can be calculated based on either the value of $A$ obtained from the regression analysis of the FRP sheet strain-slip curves at loaded ends (see Eq.11) or directly from the ultimate pullout forces (see Eq.14). Therefore, the authors collected more experimental data of the ultimate pullout forces published by other researchers (Nakaba et al. 2001, Yoshizawa et al. 2000) to evaluate the effects of concrete strength and FRP stiffness on $G_{f}$ based on more experimental databases. Only those data with bond lengths exceeding 300mm has been selected. Through Eq.15 the effects of bond width on the $G_{f}$ can be eliminated. Fig. 11.a, Fig. 11.b and Fig. 11.c show the effects of concrete strength, FRP stiffness and adhesive properties on the $G_{f}$ respectively. Since the other researchers did not study the effects of adhesives, Fig. 11.c only shows the test results of the present study. It can be found that the shear stiffness of adhesive layer affects the interfacial fracture energy most (see Fig. 11.c). The effect of the concrete strength is much less than that of the adhesive (see Fig. 11.a) but slightly greater than that of the FRP stiffness (see Fig. 11.b). The lower shear stiffness adhesives can improve the interfacial fracture energy significantly due to their good toughness (Dai et al. 2002, Dai and Ueda 2003). Through regressing, the expression for the interfacial fracture energy can be obtained as follows:

$$
G_{f}=0.446\left(G_{a} / t_{a}\right)^{-0.352} f_{c}^{0.236}\left(E_{f} t_{f}\right)^{0.023}
$$

The values of another interfacial parameter B are obtained from the regression analysis of the FRP sheet strain-slip curves at the loaded end of each specimen in the present study. The effects of FRP stiffness and adhesives on B are shown in Fig. 12.a and Fig. 12.b respectively. It can be seen that B increases insignificantly with the FRP stiffness (see Fig. 12.a) whereas increases remarkably with the shear stiffness of adhesive layer (see Fig. 12.b). Through a 
similar regressing way, the expression for B can be obtained as follows:

$$
B=6.846\left(E_{f} t_{f}\right)^{0.108}\left(G_{a} / t_{a}\right)^{0.833}
$$

Therefore, the $\tau \sim S$ relationships of FRP sheet-concrete interfaces with different properties of FRP, adhesives and concrete strength can be determined through the two calibrated parameters $\mathrm{G}_{\mathrm{f}}$ (Eq.20) and B (Eq.21).

Fig. 13.a shows the effects of FRP stiffness on the $\tau \sim s$ relationships. It can be seen that both the initial stiffness of the $\tau \sim S$ relationships and the maximum bond stresses increase slightly with the increasing of FRP stiffness. Similar effects of FRP stiffness on the maximum bond stress were included in the models proposed by Sato et al. (2000) and Lorenzis et al. (2001) in different extent. Tripi et al. (2000) also found that relative displacements between the FRP sheets and concrete are slightly affected by the elastic modulus of the sheets in their moiré interferometric analysis. The effects of FRP stiffness on the interfacial stiffness and maximum bond stress may be caused by the different strain condition in the thin concrete layer next to the adhesives. In the case of using same adhesives, higher FRP stiffness brings lower strain level in the concrete.

The dependency of $G_{f}$ and $B$ on the FRP stiffness exists but is rather small (see Fig. 11.b and Fig. 12.a). Therefore, in the case of using common adhesives such as FR-E3P, the expressions $G_{f}=0.514 f_{c}{ }^{0} 0.236$ and $B=10.4 m^{-1}$ can be obtained for the $\tau \sim$ s relationship (Eq.16) by averaging all experimental values without consideration of the FRP stiffness' effects and assuming that the shear stiffness of the adhesive is the same (see Fig. 10.a).

Fig. 13.b gives a group of $\tau \sim s$ relationships with different shear stiffness of adhesives but the same FRP stiffness (50.6 kN/mm) and concrete strength (35MPa). The comparisons between the experimental $\tau \sim \mathrm{s}$ relationships and predicted ones in cases of using adhesives other than FR-E3P are shown in Fig. 10.b and Fig. 10.c. It is obvious that the maximum interfacial bond stress increases with the shear stiffness of adhesives. When the FRP stiffness is same, this increase is caused by high strain gradients in FRP sheets in the case of using high modulus adhesives (Nishida et al. 1999, Dai et al. 2002). In the present model, the maximum bond stress decreases with the shear stiffness of adhesive due to the significant decreasing $B$, although the interfacial fracture energy $G_{f}$ can increase with the decreasing of adhesives’ shear stiffness (see Eq.19).

In fact, the value $B$ can be regarded as an index of ductility of the $\tau \sim$ s relationships, which is mainly affected by the adhesive properties. Better ductility means slower softening after the peak bond stress. Smaller B means lower initial interfacial stiffness but better interfacial ductility and vice versa. In other words, it is difficult to obtain higher 
interfacial stiffness and ductility simultaneously. This shortcoming is caused by the inherent properties of adhesives. However, it gives us a possibility to optimize the interface design according to the desirable structural performances. Fig. 14 gives comparisons of the ultimate interfacial loads predicted by the present proposed $\tau \sim s$ model and the experimental data selected from the pullout tests of FRP sheet-concrete interfaces with bond lengths exceeding $30 \mathrm{~cm}$ (Yoshizawa et al. 2000, Nakaba et al. 2001 and present study). The reasonable scattering of all data around the line of $P_{\text {ana. }} / P_{\text {exp. }}=1.0$ indicates the good accuracy of the present models on predicting the bond capacity of FRP sheet-concrete interfaces. As discussed above, the ultimate interfacial load is only related to FRP stiffness and the $G_{f}$ (the area under the $\tau \sim$ s relationship) regardless of the shape of the $\tau \sim s$ relationship. Therefore, it is a good choice to use $\mathrm{G}_{\mathrm{f}}$, which can be back-calculated from many published ultimate interfacial loads, as a control parameter when configuring any unknown $\tau \sim \mathrm{s}$ relationship. The use of $\mathrm{G}_{\mathrm{f}}$ at least can ensure the accuracy of predicting the ultimate interface bond capacity in the case of long bond length. However, the issues of predicting the initial interfacial peeling, evaluating the interfacial load-deformation behaviors or determining the effective anchorage length depend on not only the use of $G_{f}$, but also the accurate configuration of $\tau \sim \mathcal{s}$ relationship. Based on the present and other researchers' $\tau \sim$ s relationships as shown in Fig. 1, Fig. 15 gives an example of comparing the predicted strain-slip relationships at the loaded end of a FRP sheet-concrete interface, of which the FRP stiffness, concrete strength and adhesive stiffness are $50.6 \mathrm{kN} / \mathrm{mm}, 35 \mathrm{MPa}$ and $1.14 \mathrm{GPa} / \mathrm{mm}$ (FR-E3P) respectively. It can be seen that the present model and Nakaba's model give good prediction on the whole period of pullout test (before and after initial peeling). Nakaba's model gives slight underestimation on the initial interfacial stiffness. Yoshizawa's simplified bilinear model gives a good prediction on the initial interfacial stiffness but shows a big deviation when the strain of FRP becomes higher. Sato's model gives a good prediction on the maximum strain but shows a big deviation during initial ascending period. The assumption of elasto-plastic bilinear $\tau \sim s$ relationships (Sato (Yuichi) and Lorenzis) shows comparatively less accuracy.

\section{CONCLUSIONS:}

Based on the experimental and analytical studies, the following conclusions can be drawn up:

1. A simple method to determine the local bond stress-slip relationships of FRP sheet-concrete interfaces is developed. With this method, it is not necessary to put many gages on the surface of sheets as conventional ways applied in previous studies or recommended in the present bond test specifications to 
obtain the local bond stress-slip relationships. Instead, they can be simply derived from the pullout force loaded end slip curves, which can be measured accurately during the pullout bond tests.

2. Based on the proposed method and the experimental studies, the bond stress-slip relationships for FRP sheet-concrete interfaces are proposed. Only two parameters, which are the interfacial fracture energy $G_{f}$ and another constant called as interfacial ductility index B are needed in the models. The two parameters, $\mathrm{G}_{\mathrm{f}}$ and B affect the ultimate interfacial load carrying capacity and the configuration of the bond stress-slip relationship respectively. With these two parameters, the effects of all interfacial materials can be taken into account.

3. Experimental results show that the interfacial fracture energy is hardly affected by FRP stiffness, but affected by the mechanical property of adhesives most and then by the concrete strength. With the decreasing of the shear stiffness of adhesive, the interfacial fracture energy and the interfacial ductility can be improved although the maximum interfacial bond stress decreases. That leads to the improvement of the interfacial load transfer capacity. The FRP stiffness has a slight effect on the bond stress-slip relationships. The maximum bond stress increases and the interfacial ductility decreases slightly with the increasing of the FRP stiffness. However, in comparison with the effects of adhesives and concrete, the effects of FRP stiffness on the bond stress-slip relationships are insignificant.

\section{RECOMMENDATION FOR FUTURE STUDY}

Concrete properties affect the interfacial bond behaviors by both its surface condition and strength. The dependency of interfacial ductility factor B on the concrete strength needs to be observed in future study. In addition, concrete surface treatment in laboratory may be different from that in the field. The problem on how the concrete surface condition affects the interfacial parameters of $G_{f}$ and $B$ needs to be solved quantitatively based on more solid databases.

\section{ACKNOWLEDGEMENTS}

The authors would like to express their sincere thanks to Mr. Makoto Saito and Mr. Akira Kobayashi of Nippon Steel Composite Co. Ltd. for their kind offering of experimental materials. 


\section{REFERENCES}

Bizindavyi, L. and Neale, K. W. (1999). “Transfer Length and Bond Strength for Composites Bonded to Concrete.” Journal of Composites for Construction, ASCE, 3(4), 153-160.

Brosens, K. and Gemert, D. Van. (1997). “Anchorage Stresses between Concrete and Carbon Fiber Reinforced Laminates.” Non-Metallic (FRP) Reinforcement for Concrete Structures, Proceedings of Third International Symposium, Vol.1, 271-278.

Brosens, K. and Gemert, D. Van. (1999). “Anchorage Design for Externally Bonded Carbon Fiber Reinforced Polymer Laminates.” ACI, SP 188-56, 635-641.

Chajes, M. J., Finch, William. W., Januszka, T. F. and Thomson, T. A. (1996). "Bond and Force Transfer of Composite Material Plates Bonded to concrete.” ACI Structural Journal, 93(2), 208-217.

Chen, J.F. and Teng, J.G. (2001). “Anchorage Strength Models for FRP and Steel Plates Bonded to Concrete.” Journal of Structural Engineering, Vol. 127, No.7, 784-791.

Dai, J.G., Sato, Y. and Ueda, T. (2002). "Improving the Load Transfer and Effective Bond Length for FRP Composites Bonded to Concrete.” Proceedings of the Japan Concrete Institute, Vol.24, 1423-1428.

Dai, J.G. and Ueda, T. (2003). "Local Bond Stress Slip Relations for FRP Composites-concrete Interfaces.” Proceedings of FRPRCS-6, Edited by Tan, K. H., Vol. l, 143-152.

Fukuzawa, K., Numao, T., Wu, Z., Yoshizawa, H., and Mitsui, M. (1997). “Critical Strain Energy Release Rate of Interface Debonding Between Carbon Fiber Sheet and Mortar.” Non-Metallic (FRP) Reinforcement for Concrete Structures, Proceedings of Third International Symposium, Vol.1, 295-301.

Horiguchi, T. (1997). "Effect of Test Methods and Quality of Concrete on bond strength of CFRP Sheet." Non-Metallic (FRP) Reinforcement for Concrete Structures, Proceedings of Third International Symposium, Vol.1, 265-270.

JCI TC 952 on Continuous Fiber Reinforced Concrete. (1998). “Technical Report on Continuous Fiber Reinforced Concrete.” Japan Concrete Institute (JCI).

JIS K7113 (1995). “Testing Method for Tensile Properties of Plastics.”

Karbhari, V.M. and Engineer, M. (1996). "Investigation of Bond between Concrete and Composites: Use of a Peeling Test.” Journal of Reinforced Plastics and Composites, Vol.15, 208-227. 
Lee, Y. J., Boothby T. E., Bakis, C.E., and Nanni, A. (1999). “Slip Modulus of FRP Sheets Bonded to Concrete.” Journal of Composites for Construction, ASCE, 3(4), 161-167.

Leung, C. K. Y. (2001). “Delamination Failure in Concrete Beams Retrofitted with a Bonded Plate.” Journal of Materials in Civil Engineering, ASCE, 13(2), 106-113.

Lorenzis, L. De., Miller, B., and Nanni, A. (2001). “Bond of Fiber-Reinforced Polymer Laminates to Concrete.” ACI Material Journal, 98(3), 256-264.

Maeda, T., Asano, Y., Sato, Y., Ueda, T., and Kakuta, Y. (1997). “A Study on Bond Mechanism of Carbon Fiber Sheet.” Non-Metallic (FRP) Reinforcement for Concrete Structures, Proceedings of Third International Symposium, Vol.1, 279-286.

Mitsui, M., Fukuzawa, K., Numao, T. and Fuda, I. (2000). “Relations between Surface Roughness Indexes and Bond strength between CFRP sheets and Concrete.” Journal of Society Material Science. Japan, 49(6), 685-691 (In Japanese).

Miller, B. and Nanni, A. (1999). “Bond between CFRP Sheets and Concrete.” Proc. of ASCE $5^{\text {th }}$ Materials Congress, Edited by L.C. Band, Cincinnati, OH, May 10-12, 240-247.

Nakaba, K., Kanakubo, T., Furuta, T., and Yoshizawa, H. (2001). “Bond Behavior between Fiber-Reinforced Polymer Laminates and Concrete.” ACI Structural Journal, 98(3), 359-167.

Nishida, H., Simomura, T., Kamiharako, A., and Maruyama, K. (1999). "Bond Behaviors between the FRP Sheets and concrete.” Proceedings of JCI, 21(3), 1507-1511 (in Japanese).

Sato, Y. (Yuichi), Kimura, K., and Kobatake, Y. (1997). "Bond Behaviors between CFRP Sheet and Concrete.” Journal of Structural Construction Engineering, AIJ, No.500, 75-82 (in Japanese).

Sato, Y., Asano, Y., and Ueda, T. (2000). “Fundamental Study on Bond Mechanism of Carbon Fiber Sheet.” Concrete Library International, JSCE, No.37, June 2001, 97-115.

Shima, H., Chou, L., and Okamura, H. (1987). “Bond stress-slip-strain relationship of deformed bars embedded in massive concrete.” Concrete Library International, JSCE, No.10, 79-94.

Täljsten, B. (1996). “Strengthening of Concrete Prisms Using the Plate-bonding Technique.” International Journal of Fracture, 82, 253-266.

Täljsten, B. (1997). “Defining anchor lengths of steel and CFRP plates bonded to concrete.” International Journal of Adhesion and Adhesives, 17(4), 319-327. 
Tripi, J. M., Bakis, C. E., Boothby, T. E., and Nanni, A. (2000). "Deformation in Concrete with Externally CFRP Sheet Reinforcement.” Journal of Composites for Construction, Vol. 4, No.2, 85-94.

Ueda, T., Sato, Y., and Asano, Y. (1999). "Experimental Study on Bond strength of Continuous Carbon Fiber Sheet.” ACI, SP 188-37, 407-413.

Wu, Z. and Yin, J. (2002). "Numerical Analysis on Interfacial Fracture Mechanism of Externally FRP-Strengthened Structural Members.” Journal of Materials, Conc. Struct. Pavements, JSCE, No.704/V-55, 257-270.

Yoshizawa, H., Wu, Z., Yuan, H., and Kanakubo, T. (2000). "Study on FRP-Concrete Interface Bond Performance.” Transactions of Japanese Society of Civil Engineering, No.662/V-49, 105-119.

Yin, J. and Wu, Z. (1999). "Interface Crack Propagation in Fiber Reinforced Polymer-strengthened Concrete Structures Using Nonlinear Fracture Mechanics.” ACI, SP 188-87, 1035-1047.

Yuan, H., Wu, Z., and Yoshizawa, H. (2001). “Theoretical Solutions on Interfacial Stress Transfer of Externally Bonded Steel/Composite Plates.” J. Structural. Mech.Earthquake Eng. JSCE, 18(1), 27-39. 


\section{FIGURES:}

Note: the figures at final size with desired reduction are provided in another document

Fig. $1 \quad(17.78 \mathrm{~cm}$ wide, suggest $50 \%$ reduction)

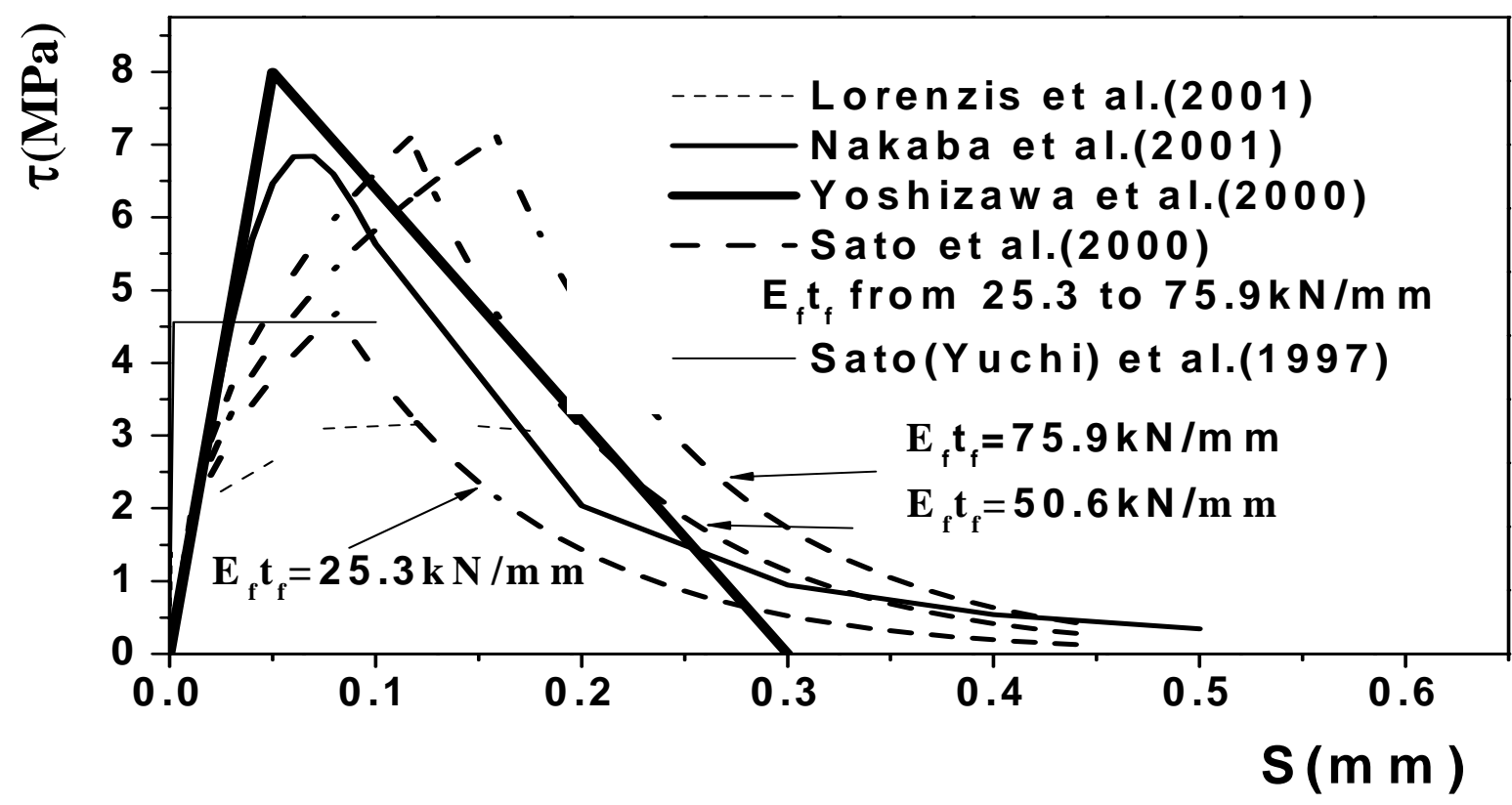


Fig. $2(17.78 \mathrm{~cm}$ wide, suggest $50 \%$ reduction)

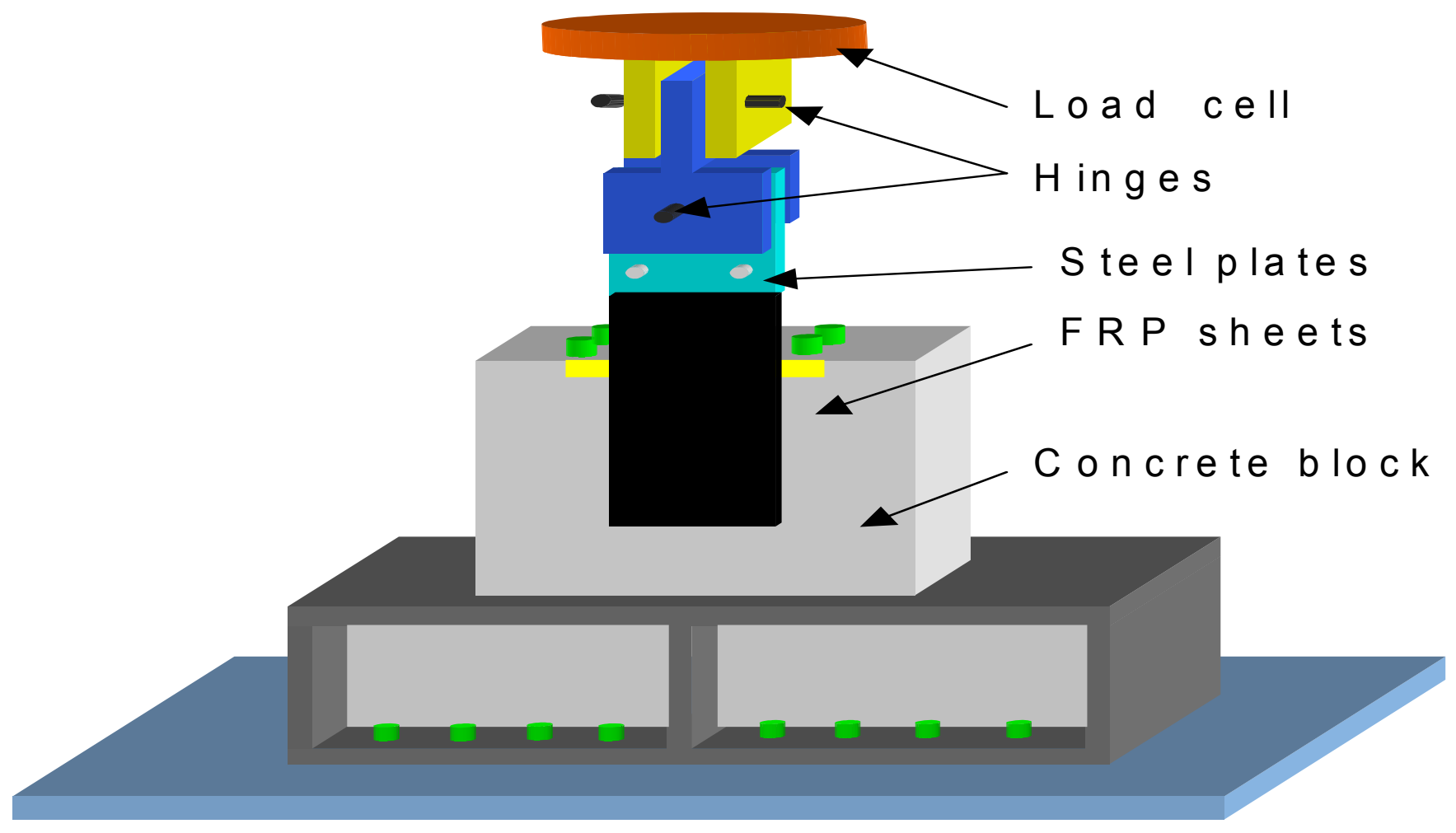


Fig. $3(17.78 \mathrm{~cm}$ wide, suggest $50 \%$ reduction)

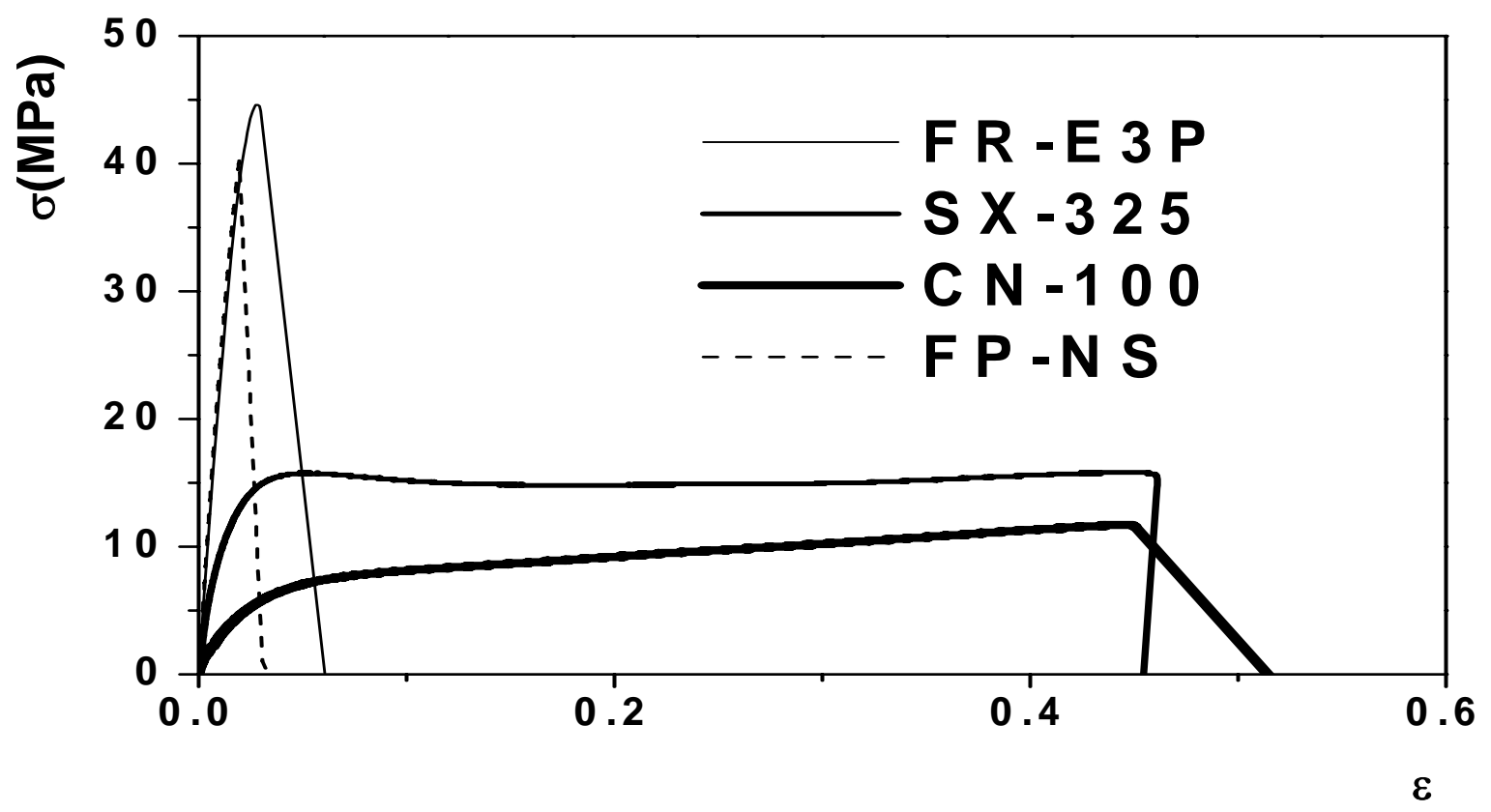


Fig. $4(17.78 \mathrm{~cm}$ wide, suggest $50 \%$ reduction)

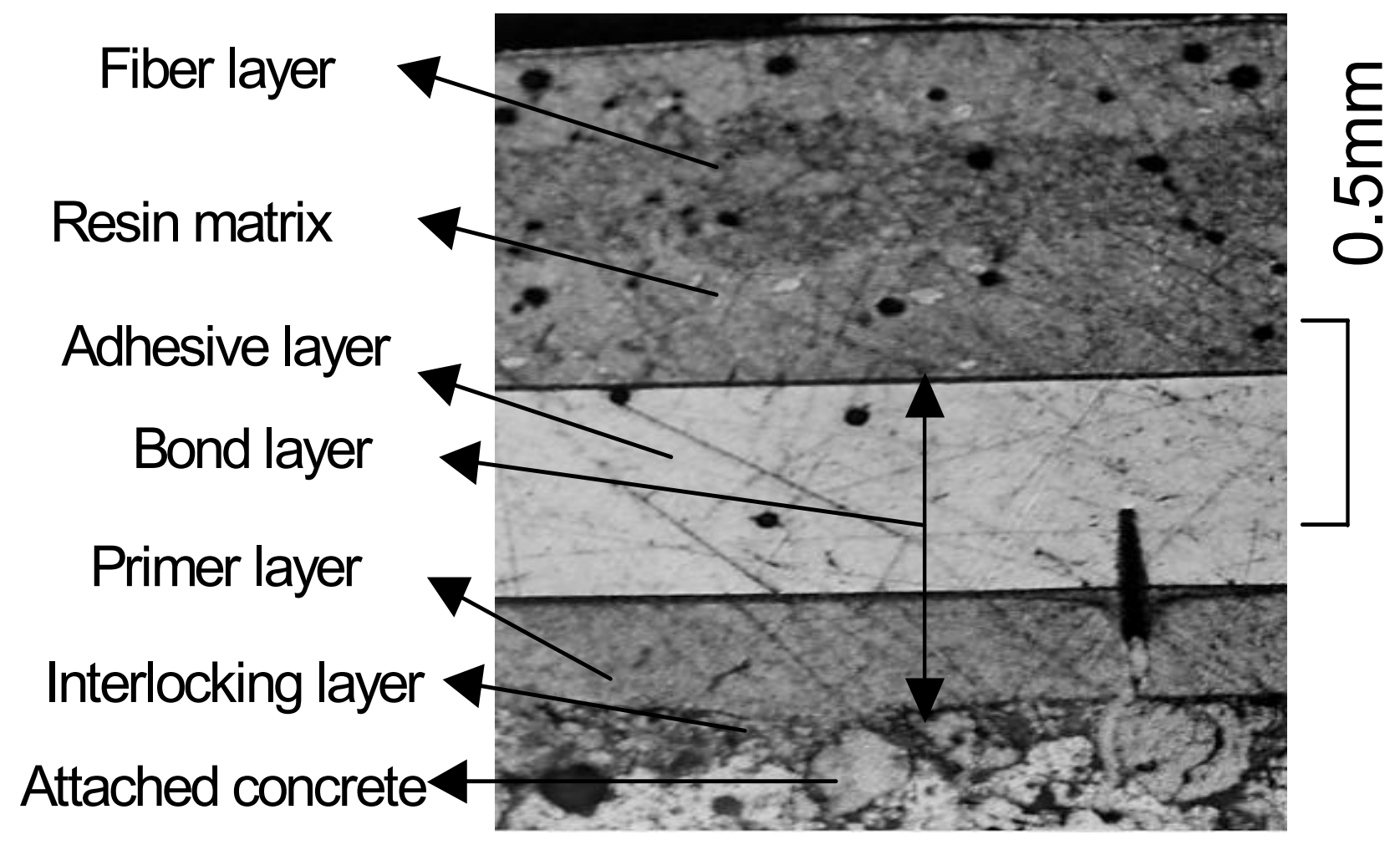


Fig. $5(17.78 \mathrm{~cm}$ wide, suggest $50 \%$ reduction)

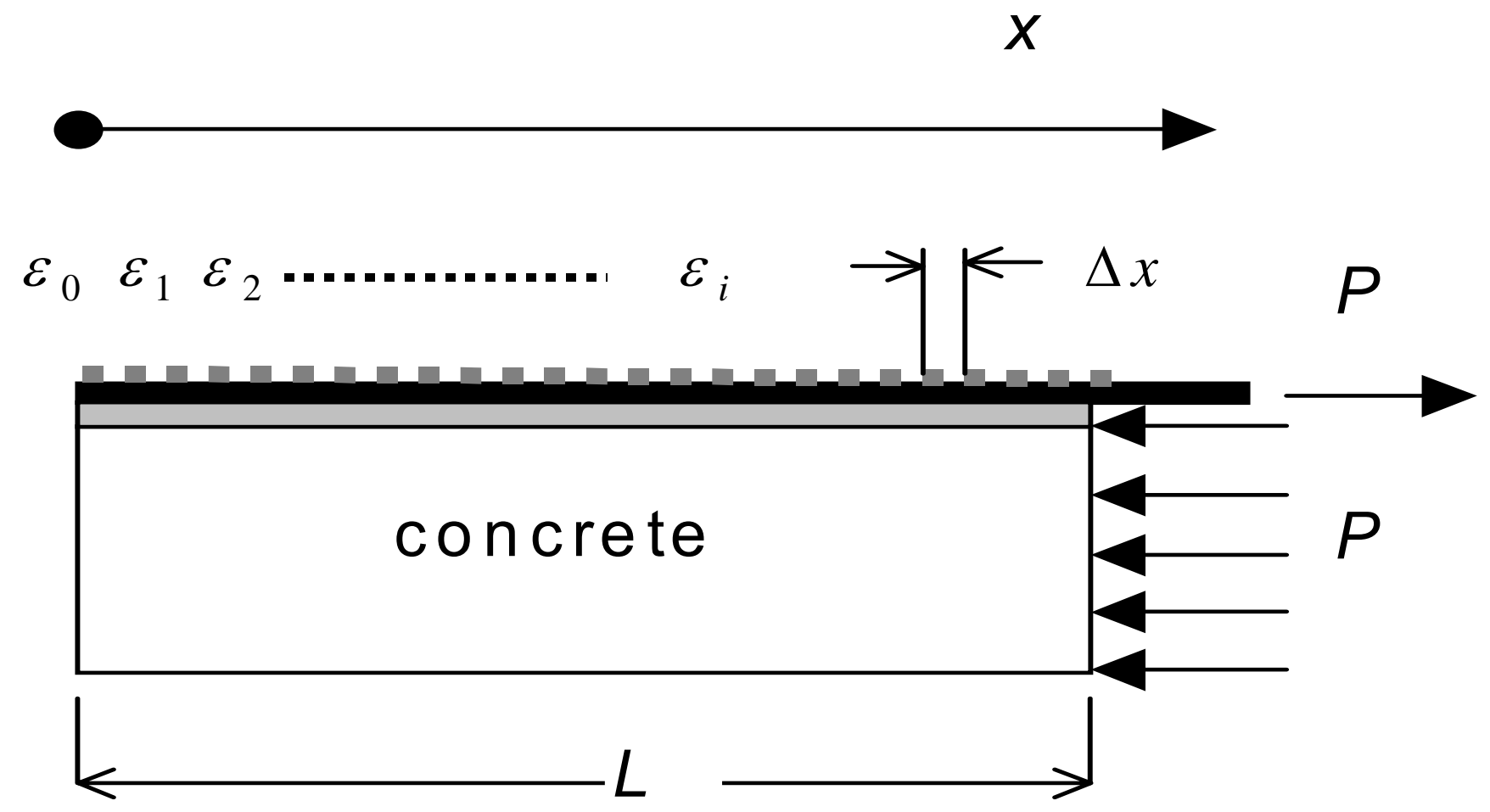


Fig. 6 (17.78 wide, suggest 50\% reduction)

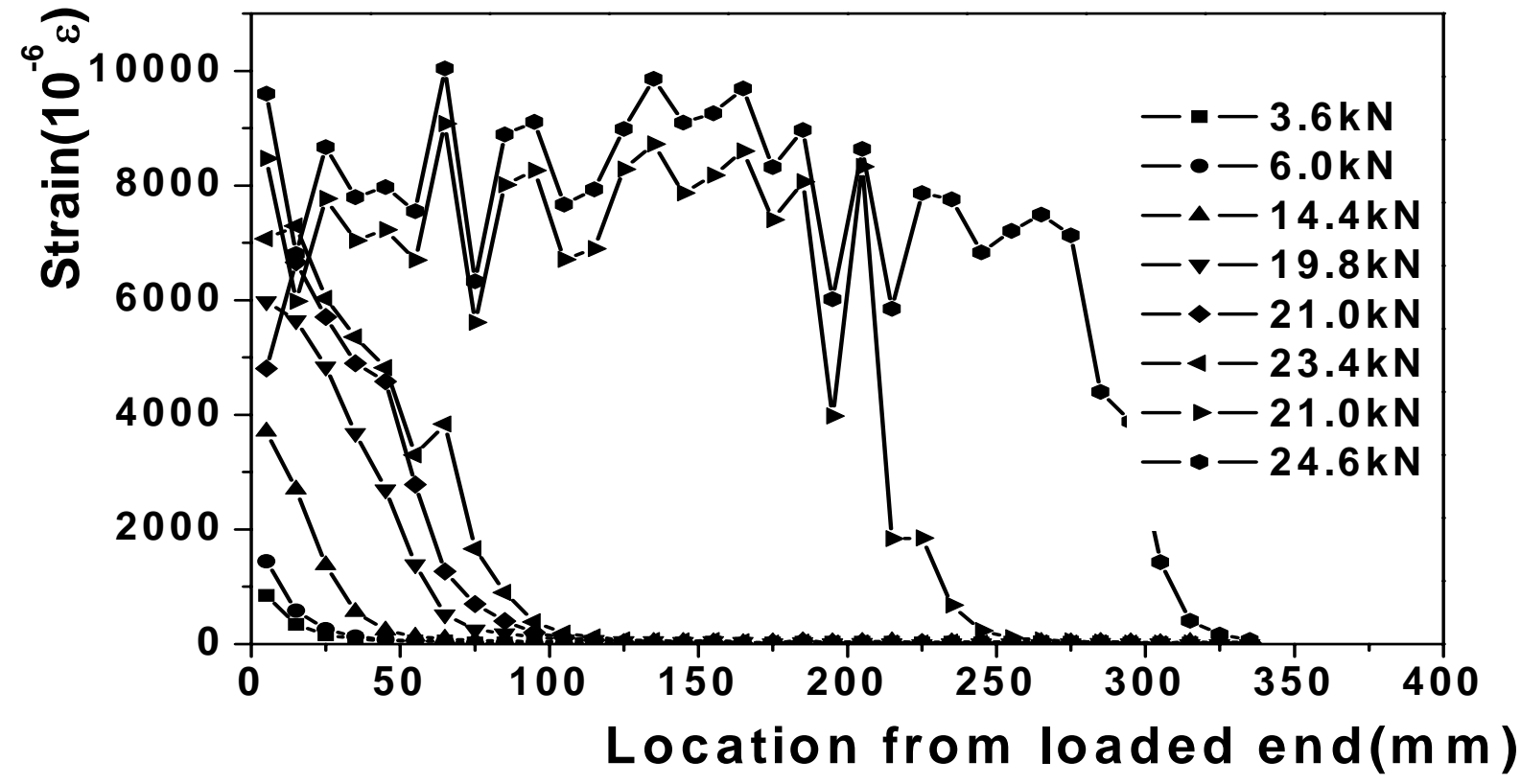


Fig. 7 (17.78cm wide, suggest $50 \%$ reduction)

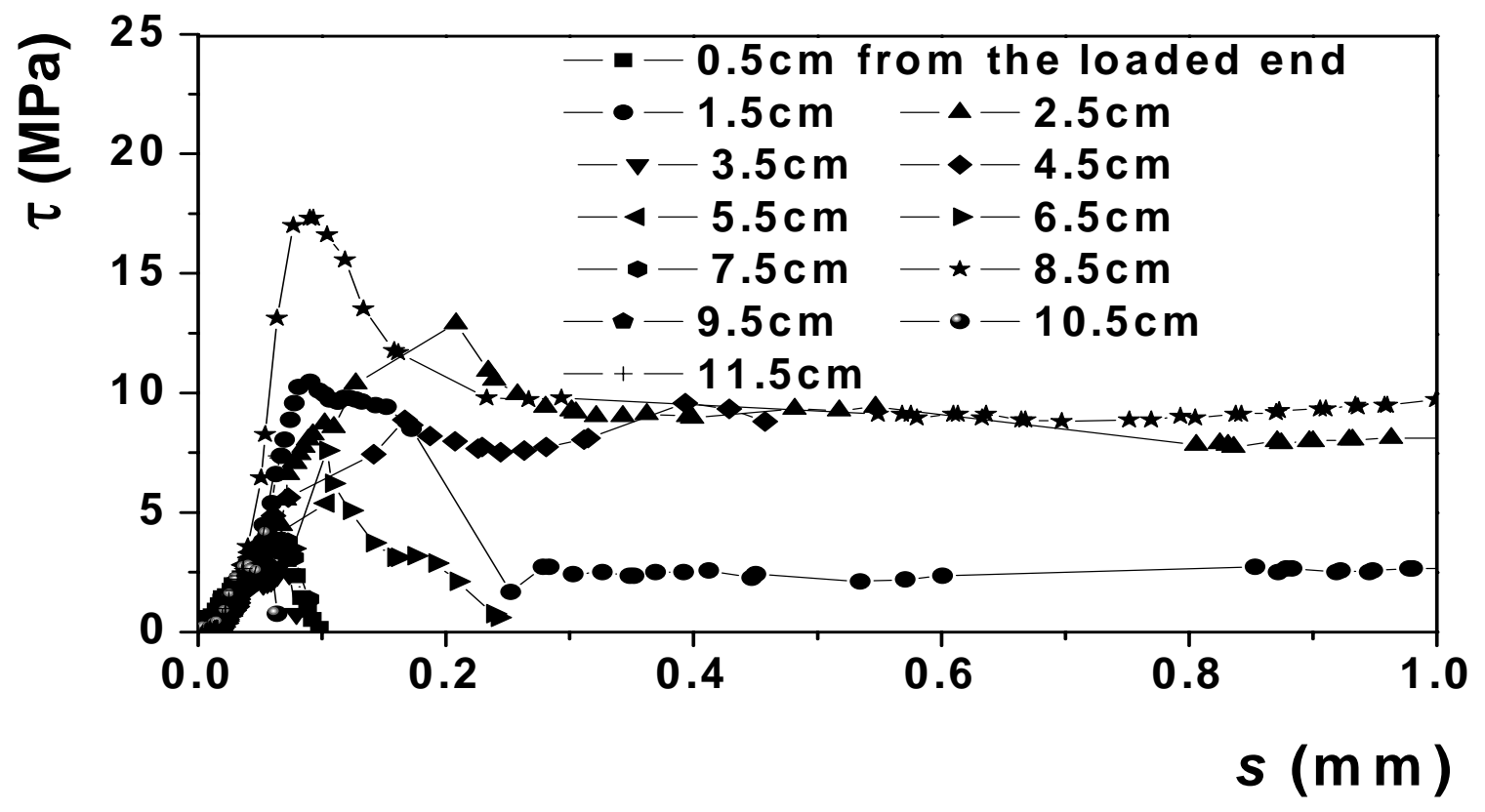


Fig. 8.a ((17.78cm wide, suggest reduction to $33 \%)$

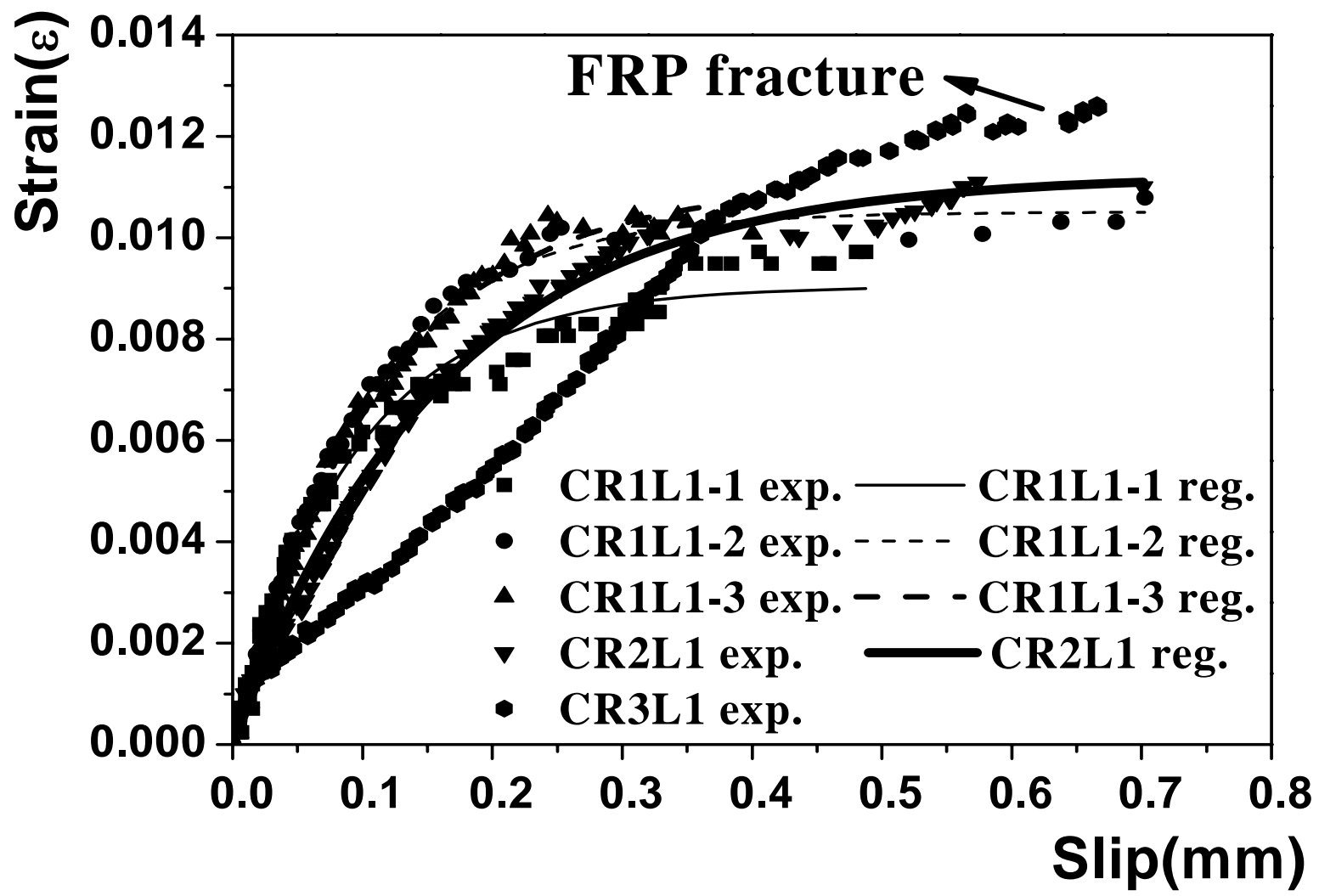


Fig. 8.b (17.78cm wide, suggest reduction to $33 \%)$

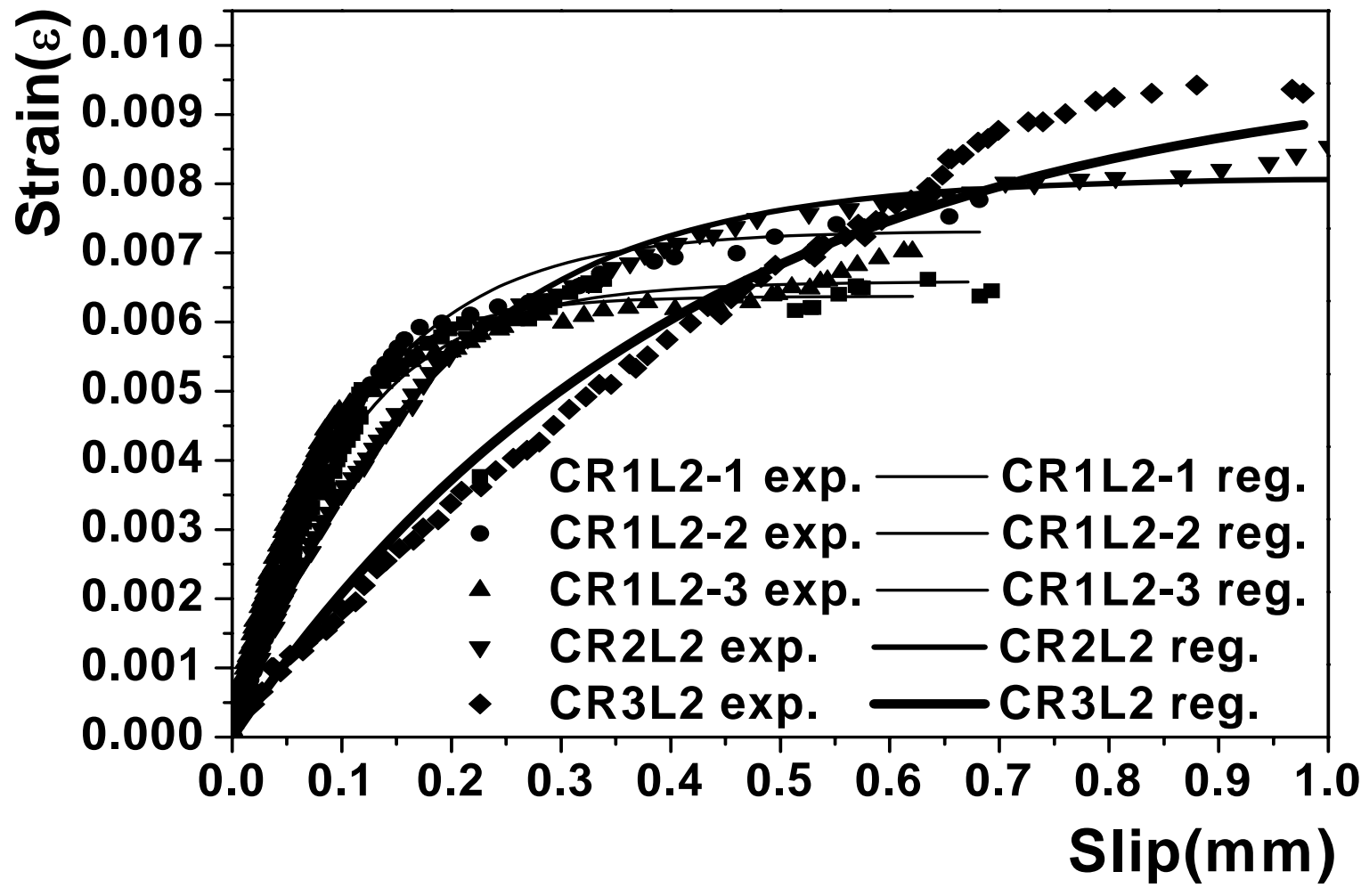


Fig. 8.c ((17.78cm wide, suggest reduction to 33\%)

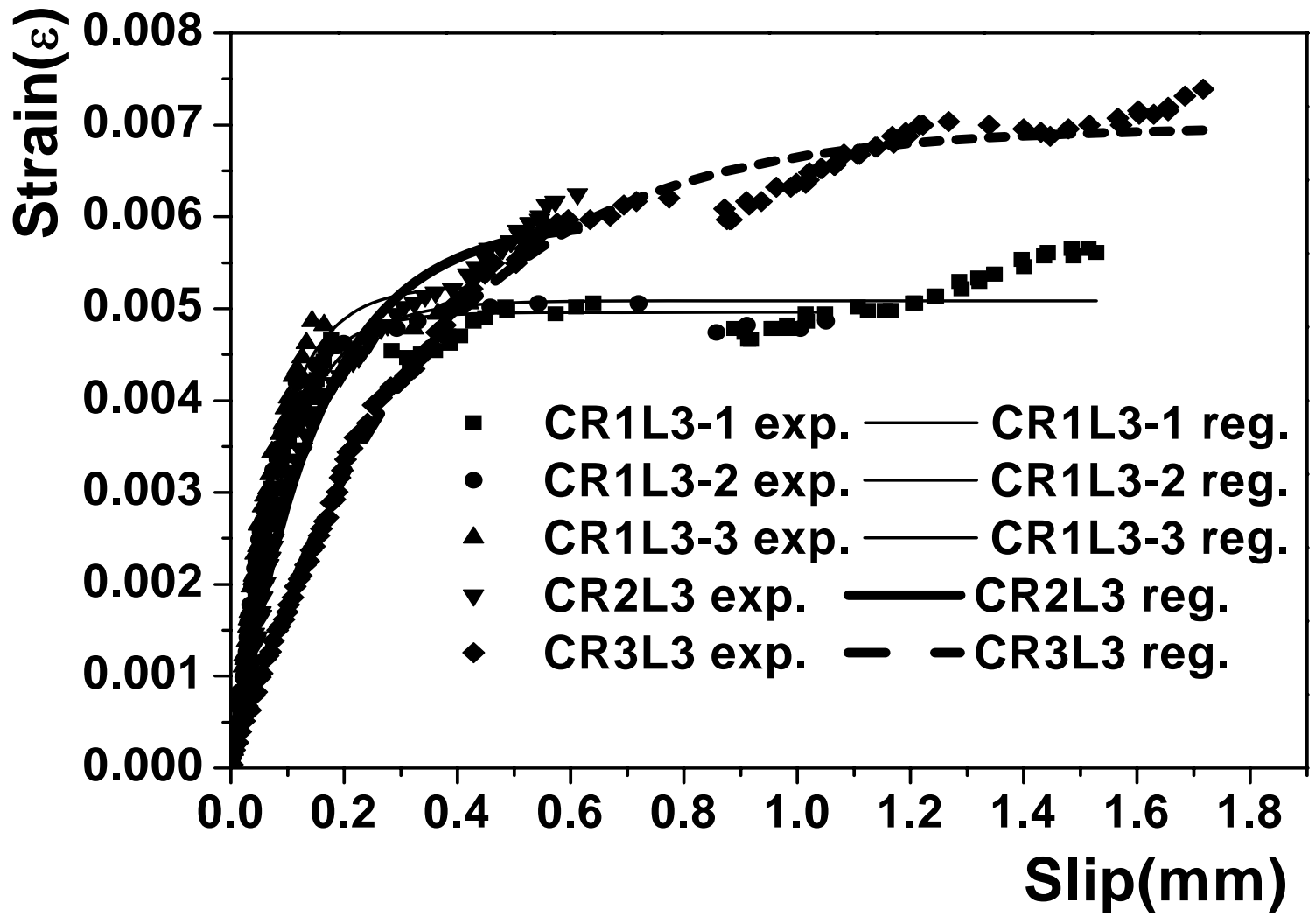


Fig. $8 . d(17.78 \mathrm{~cm}$ wide, suggest reduction to $33 \%)$

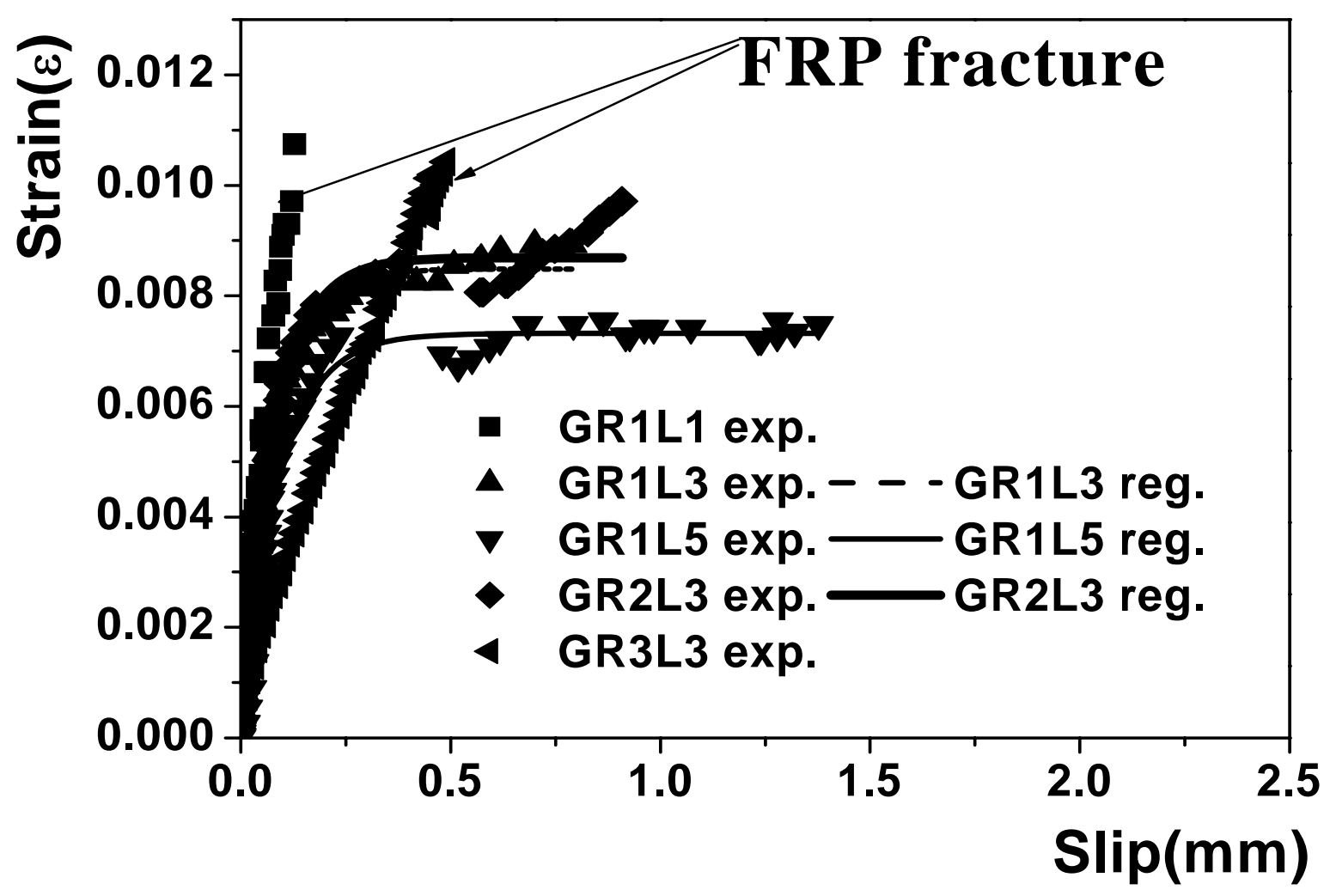


Fig. 8.e(17.78cm wide, suggest reduction to $33 \%)$

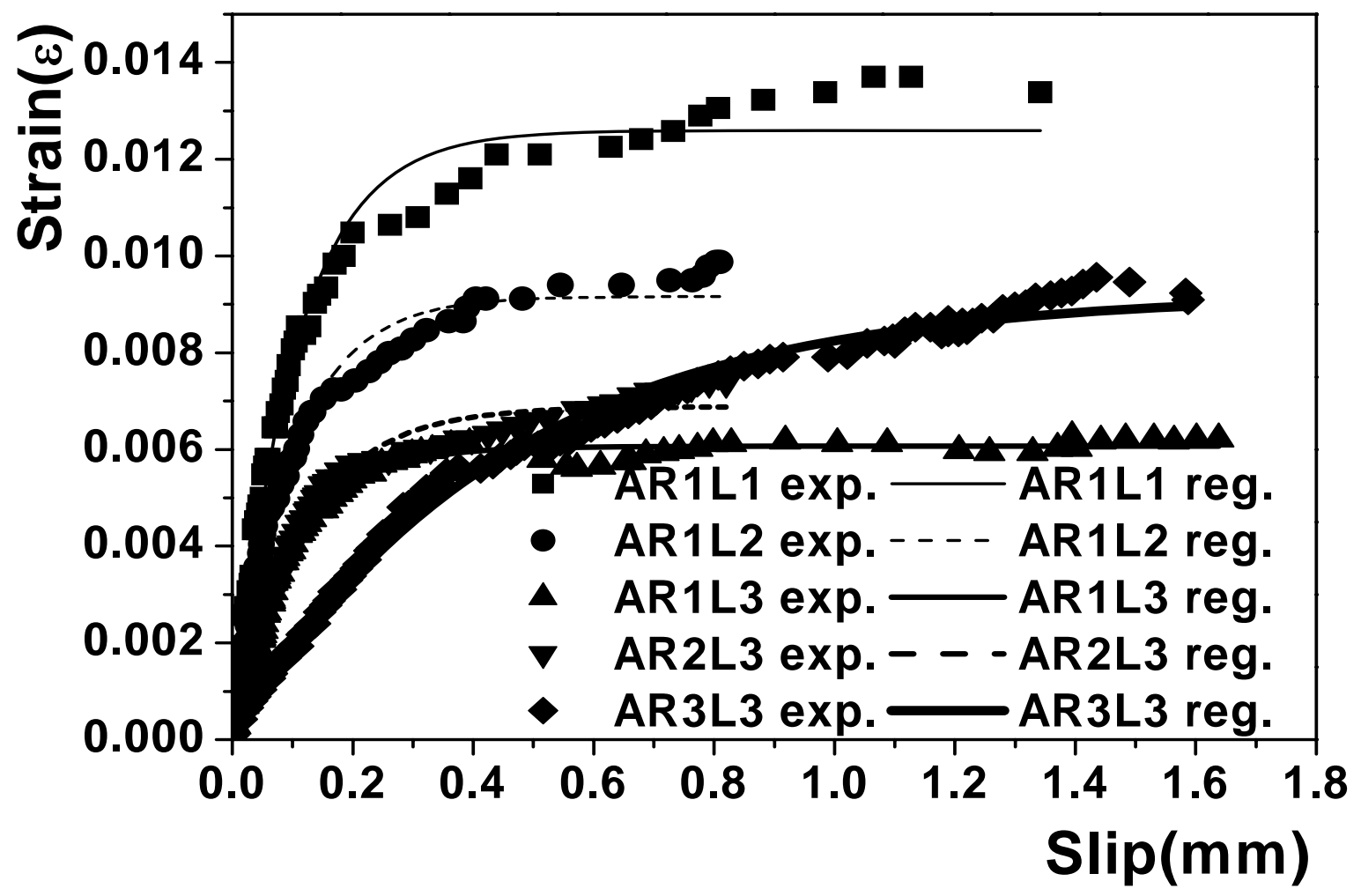


Fig. $9(17.78 \mathrm{~cm}$ wide, suggest reduction to $50 \%)$

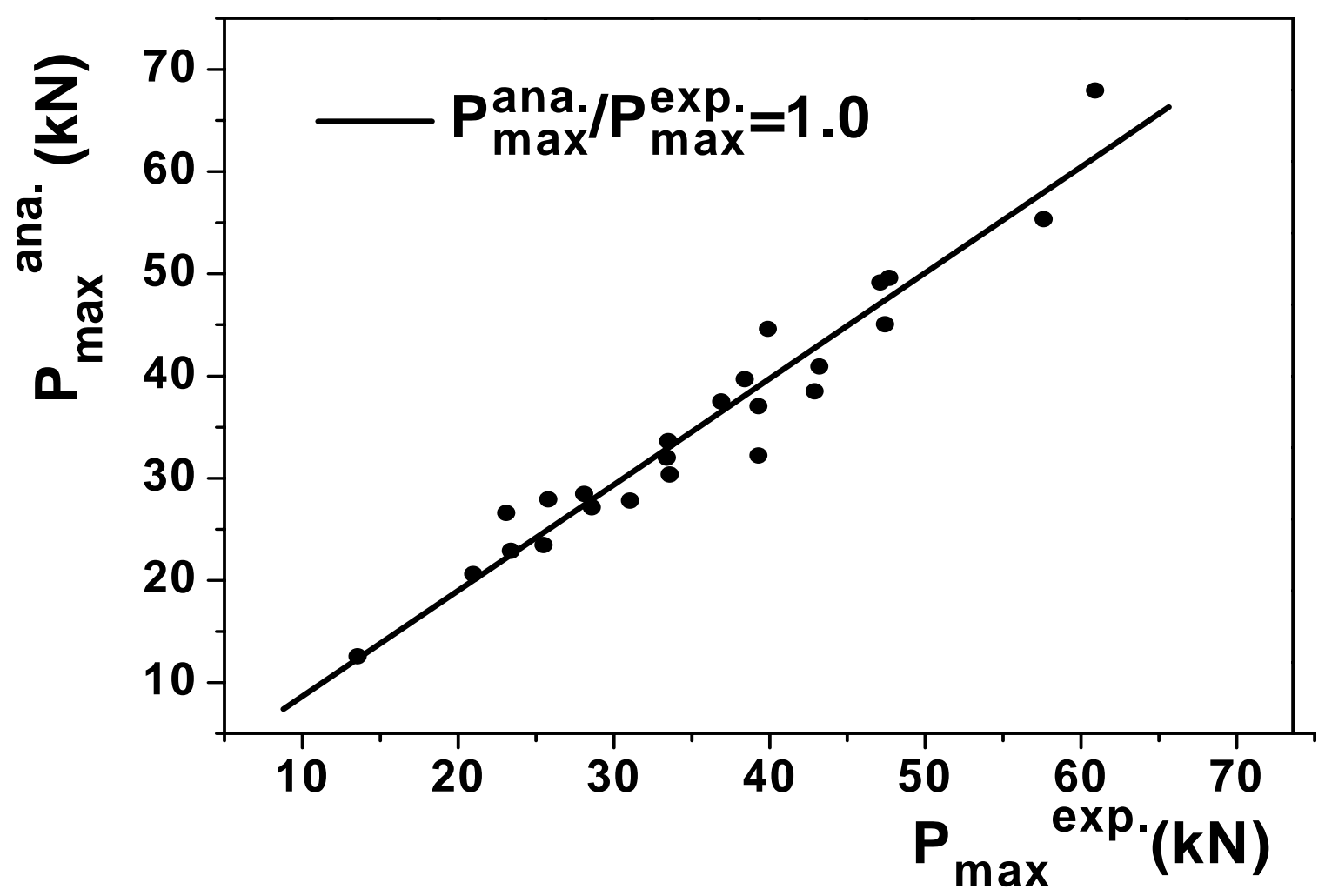


Fig. 10.a (17.78cm wide, suggest reduction to $33 \%)$

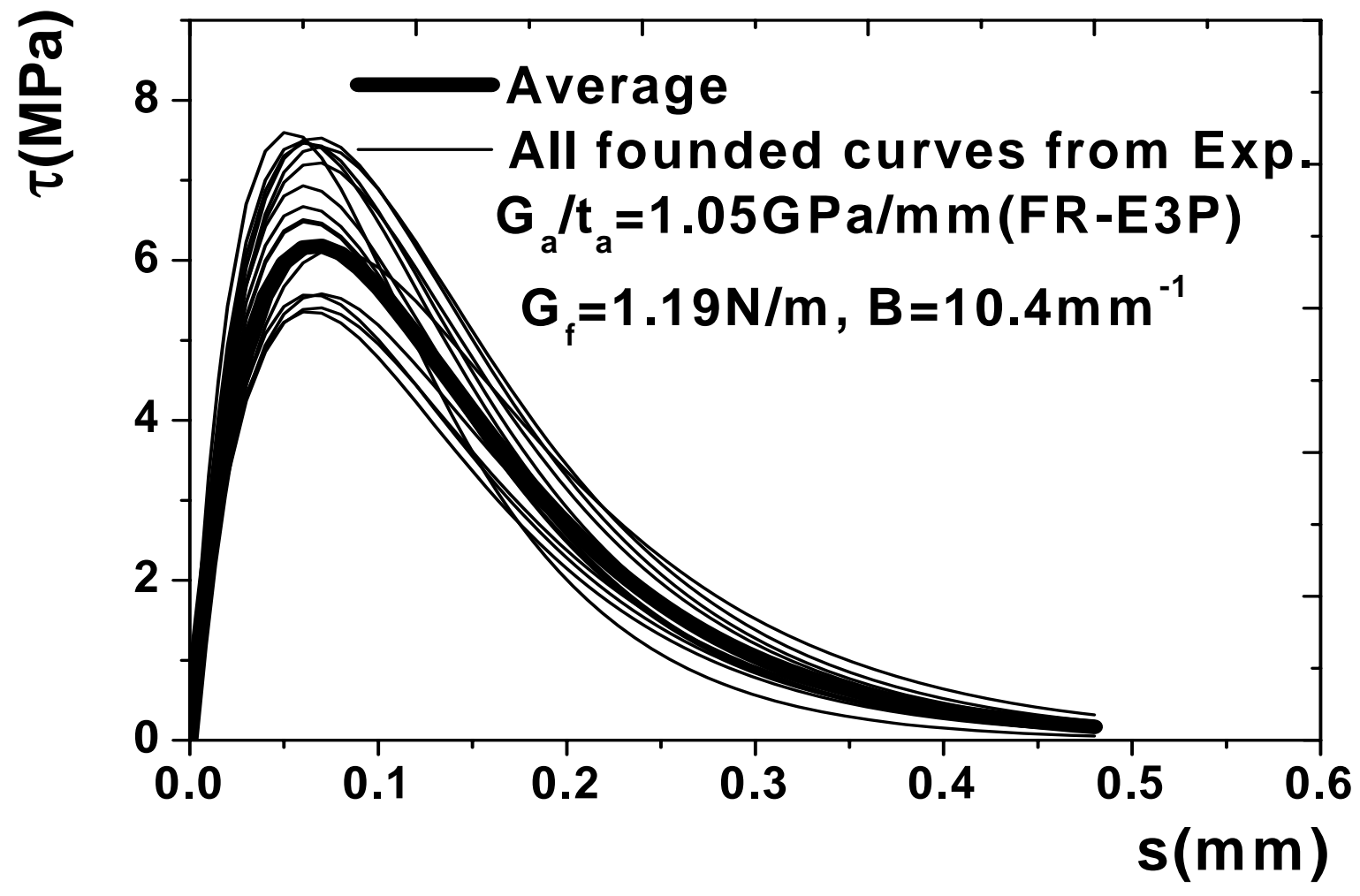


Fig. $10 . b(17.78 \mathrm{~cm}$ wide, suggest reduction to $33 \%)$

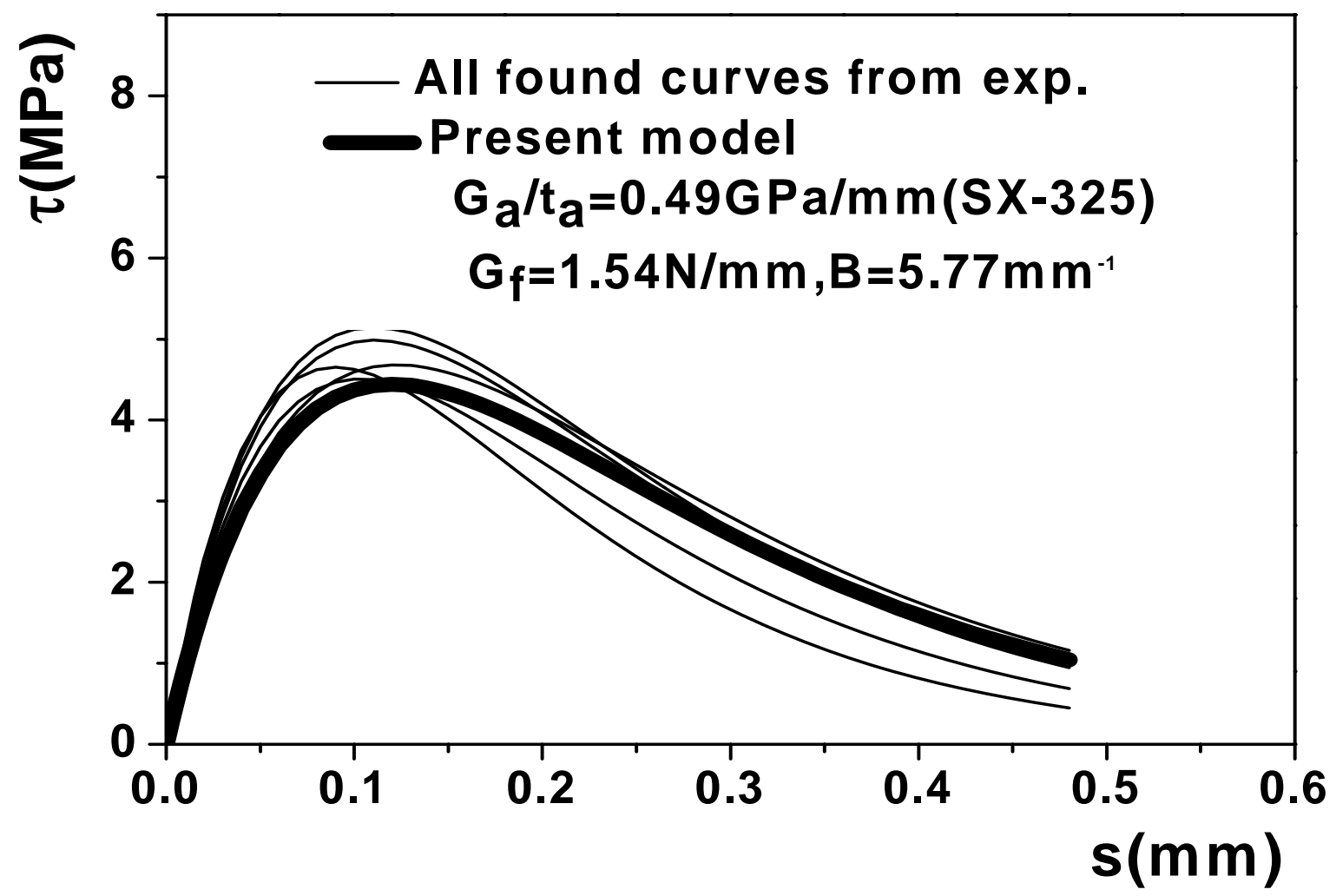


Fig. 10.c (17.78cm wide, suggest reduction to $33 \%)$

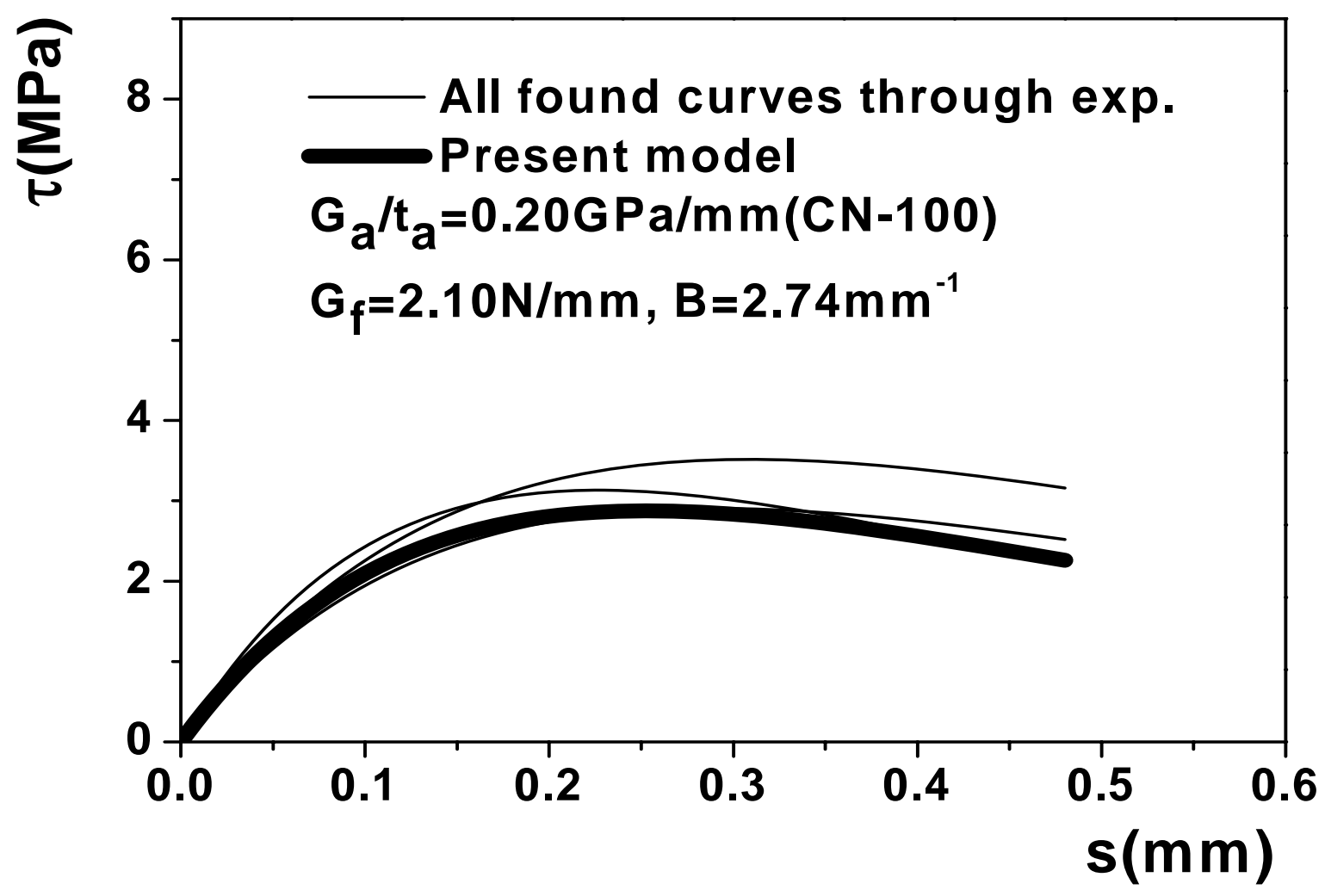


Fig. 11.a (17.78cm wide, suggest reduction to $33 \%)$

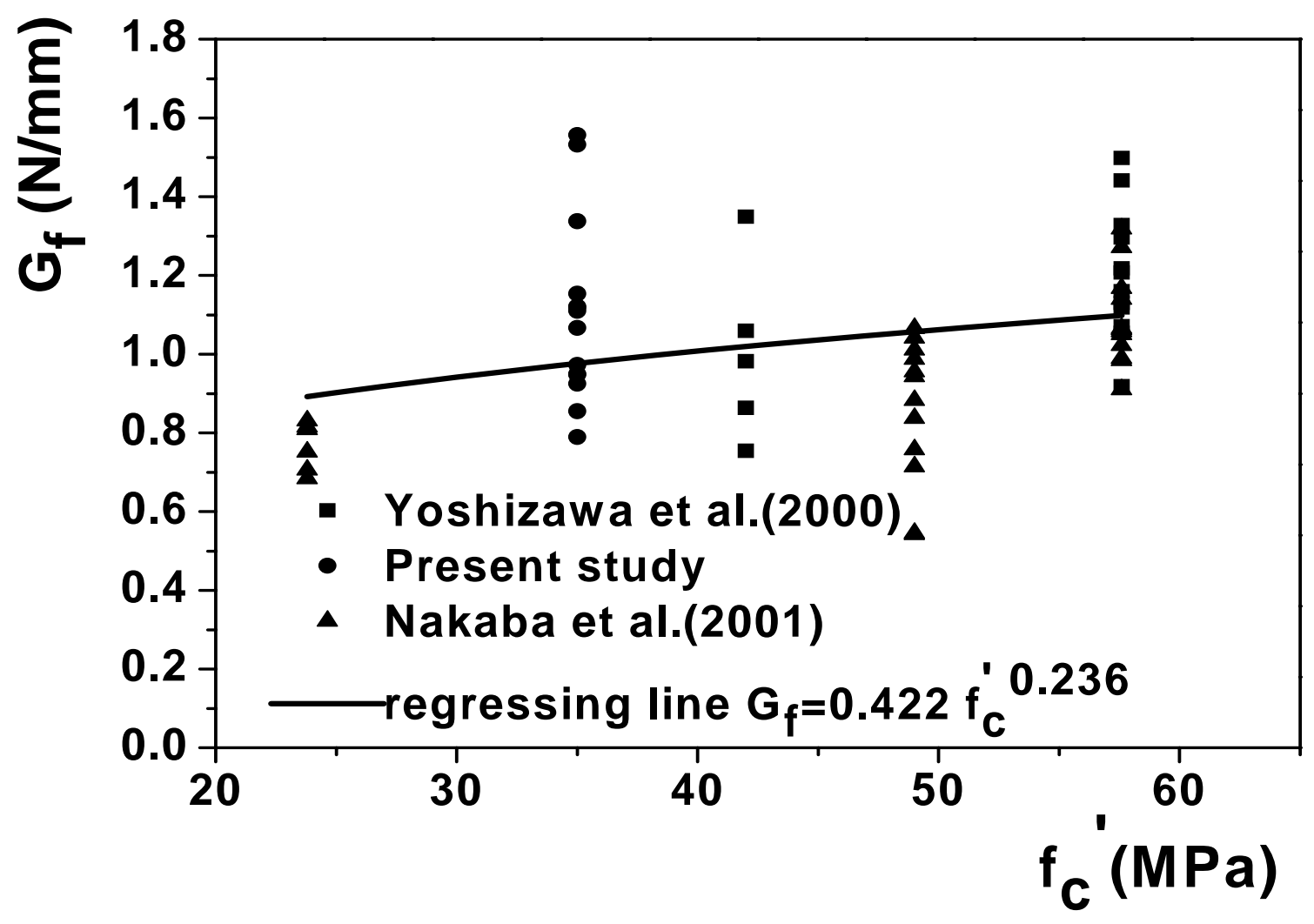


Fig. $11 . b(17.78 \mathrm{~cm}$ wide, suggest reduction to $33 \%)$

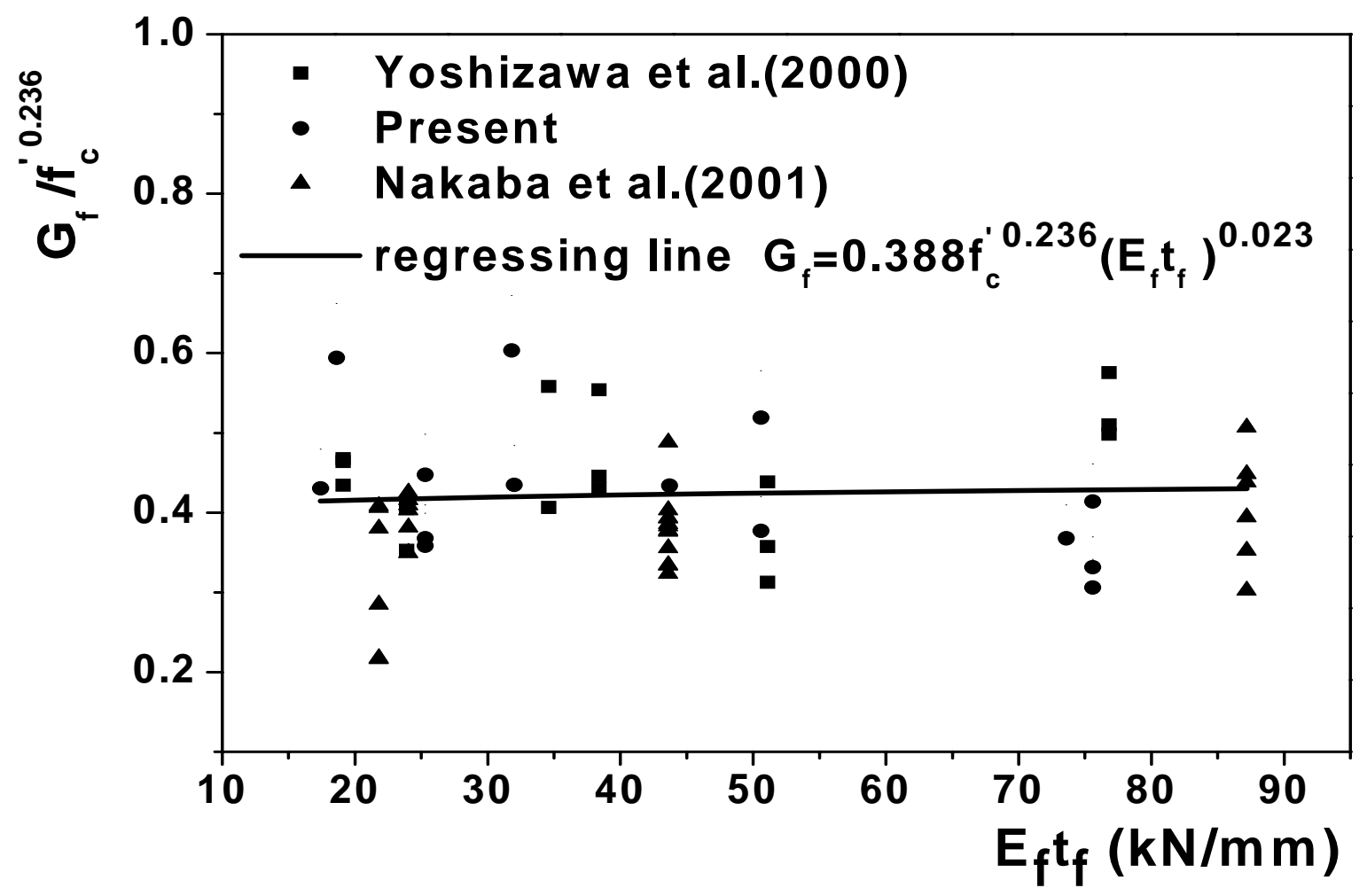


Fig. 11.c (17.78cm wide, suggest reduction to 33\%)

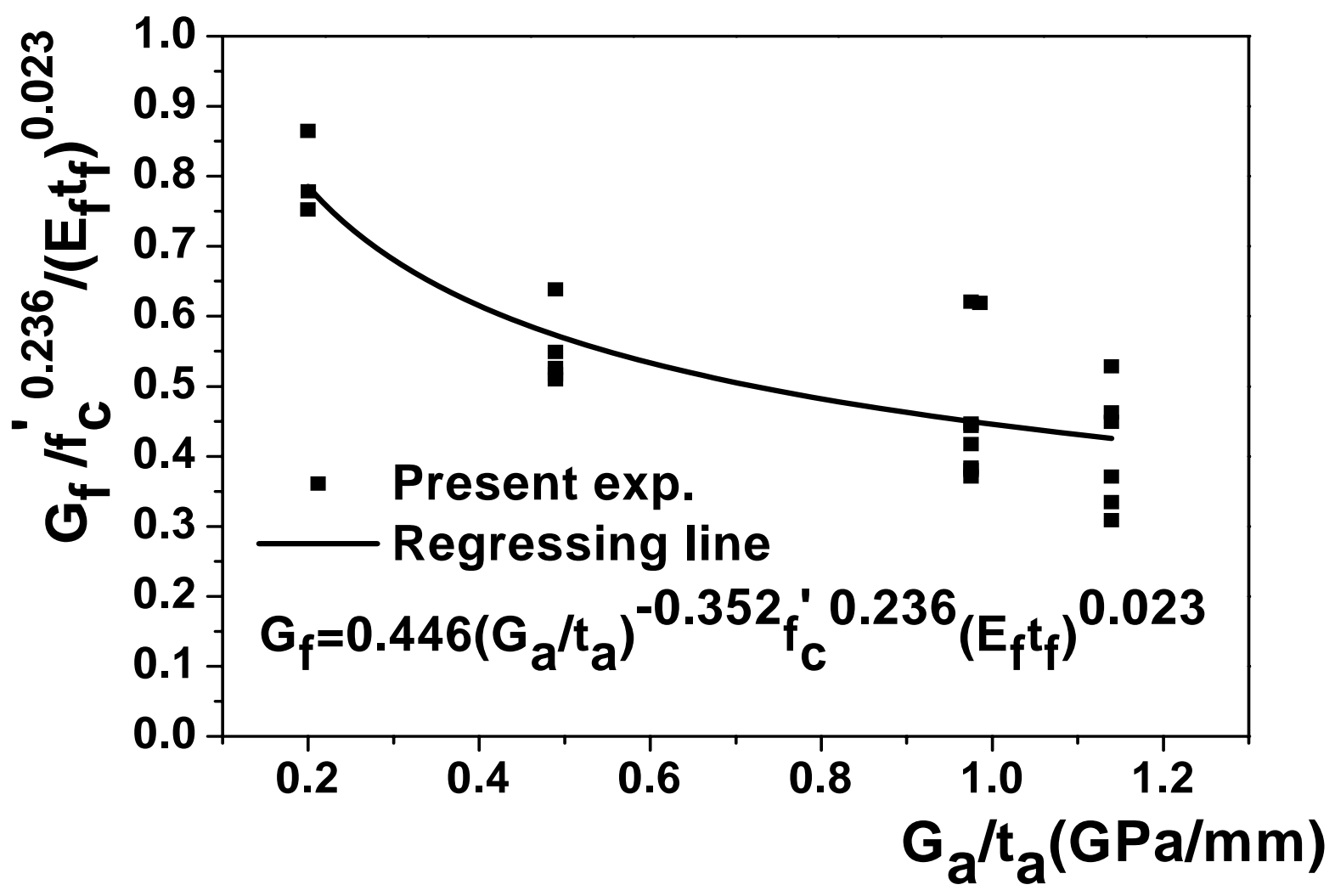


Fig. 12.a (17.78cm wide, suggest reduction to $33 \%)$

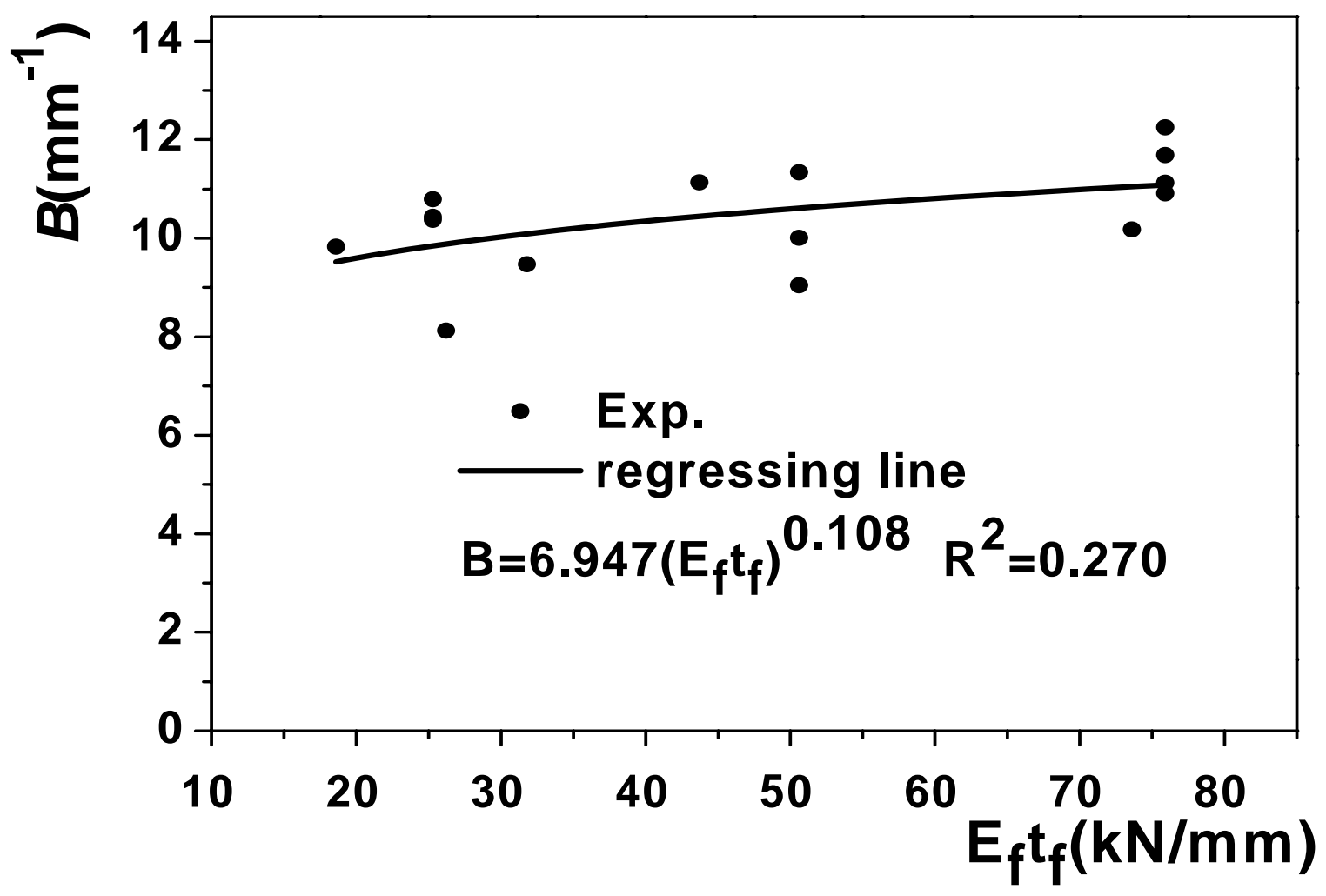


Fig. $12 . b(17.78 \mathrm{~cm}$ wide, suggest reduction to $33 \%)$

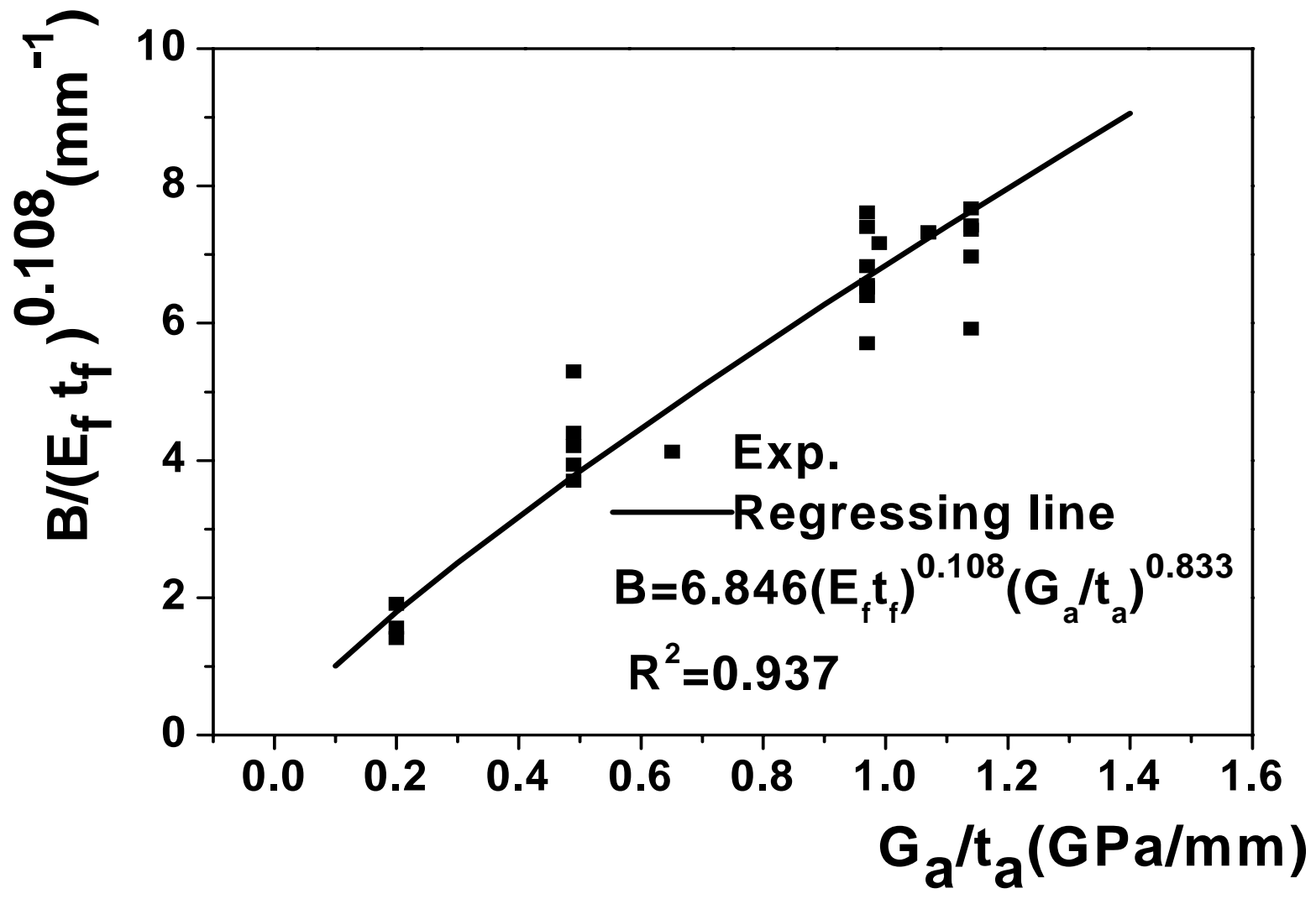


Fig. 13.a (17.78cm wide, suggest reduction to $33 \%$ )

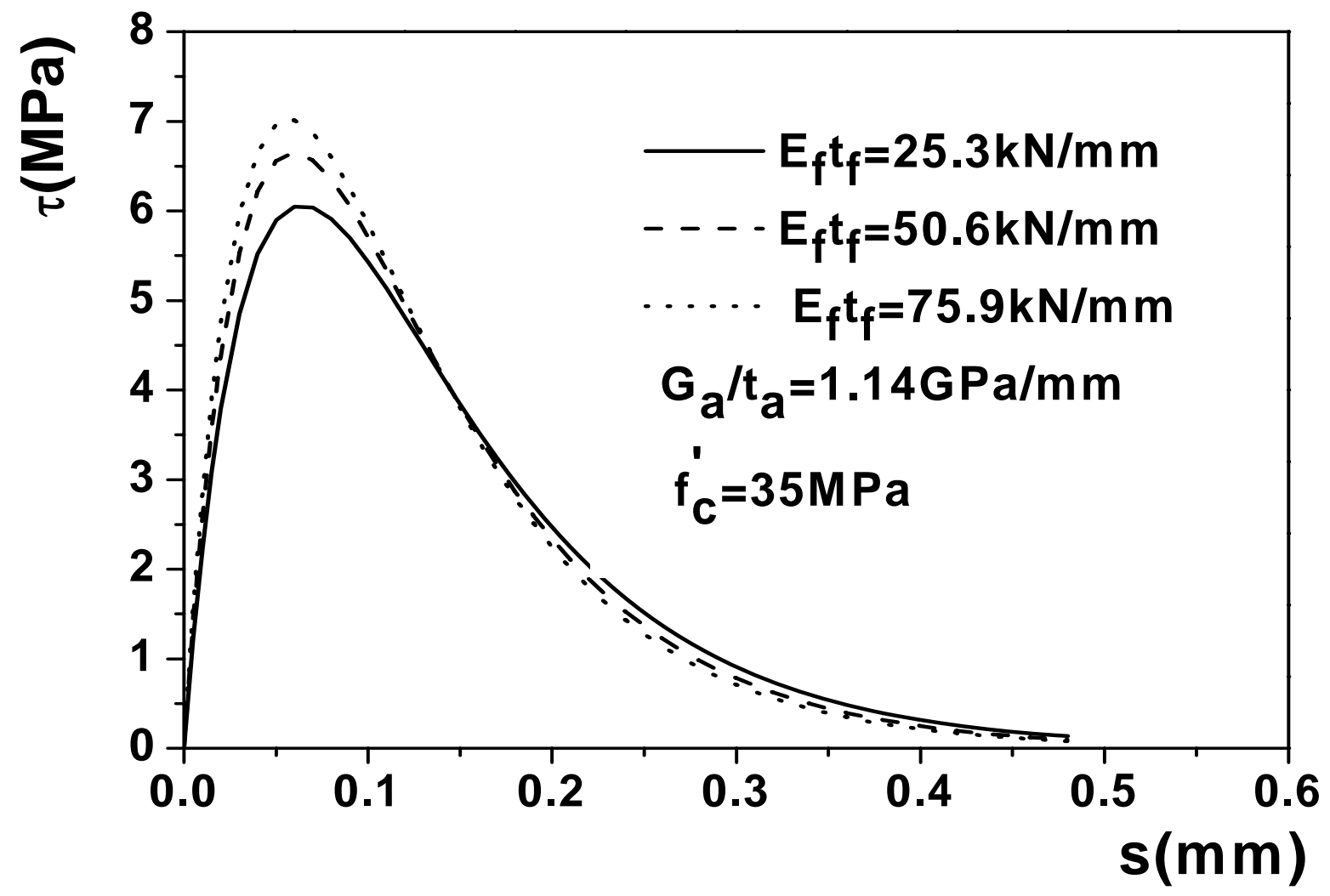


Fig. 13.b (17.78cm wide, suggest reduction to $33 \%$ )

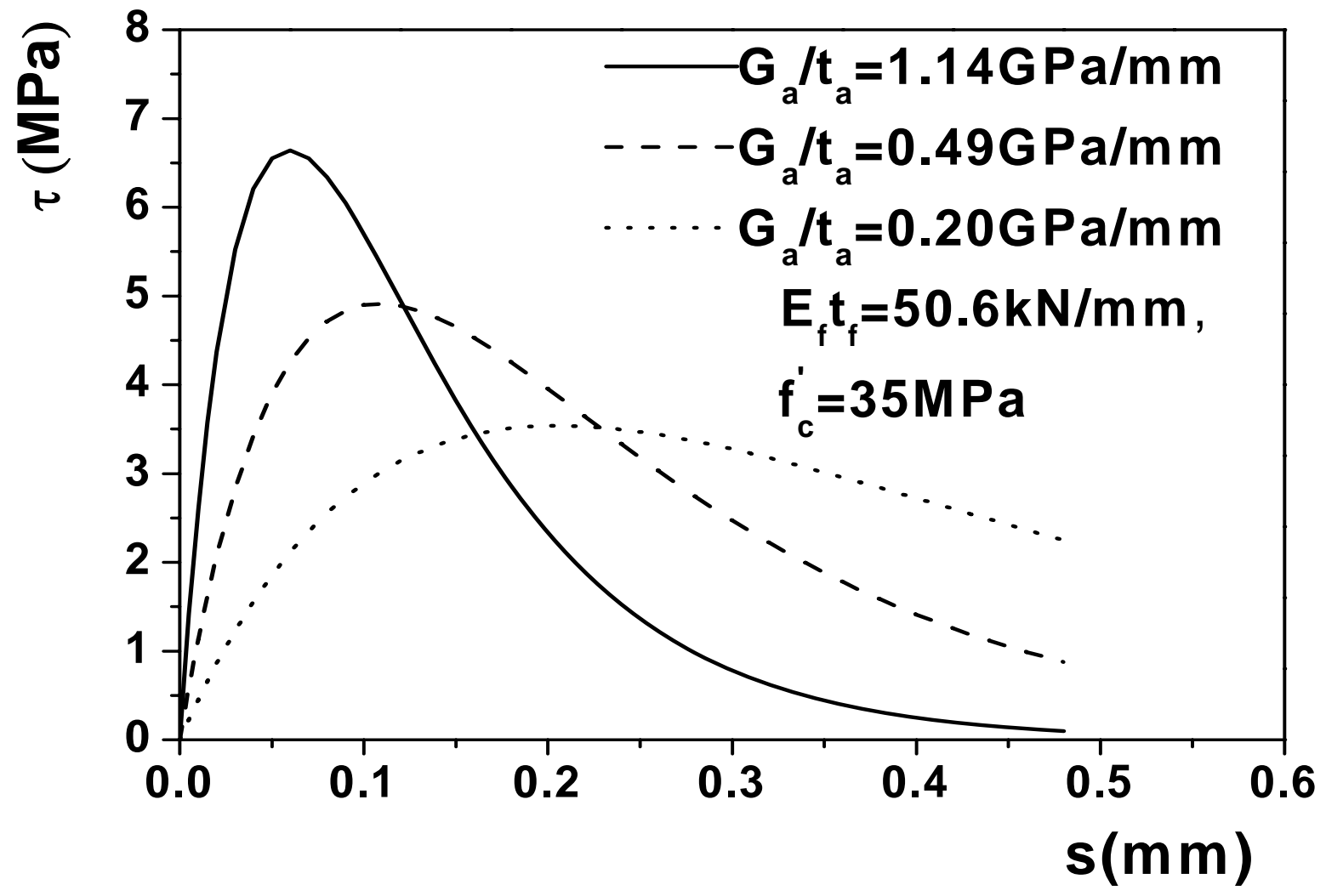


Fig.14 ((17.78cm wide, suggest reduction to 50\%)

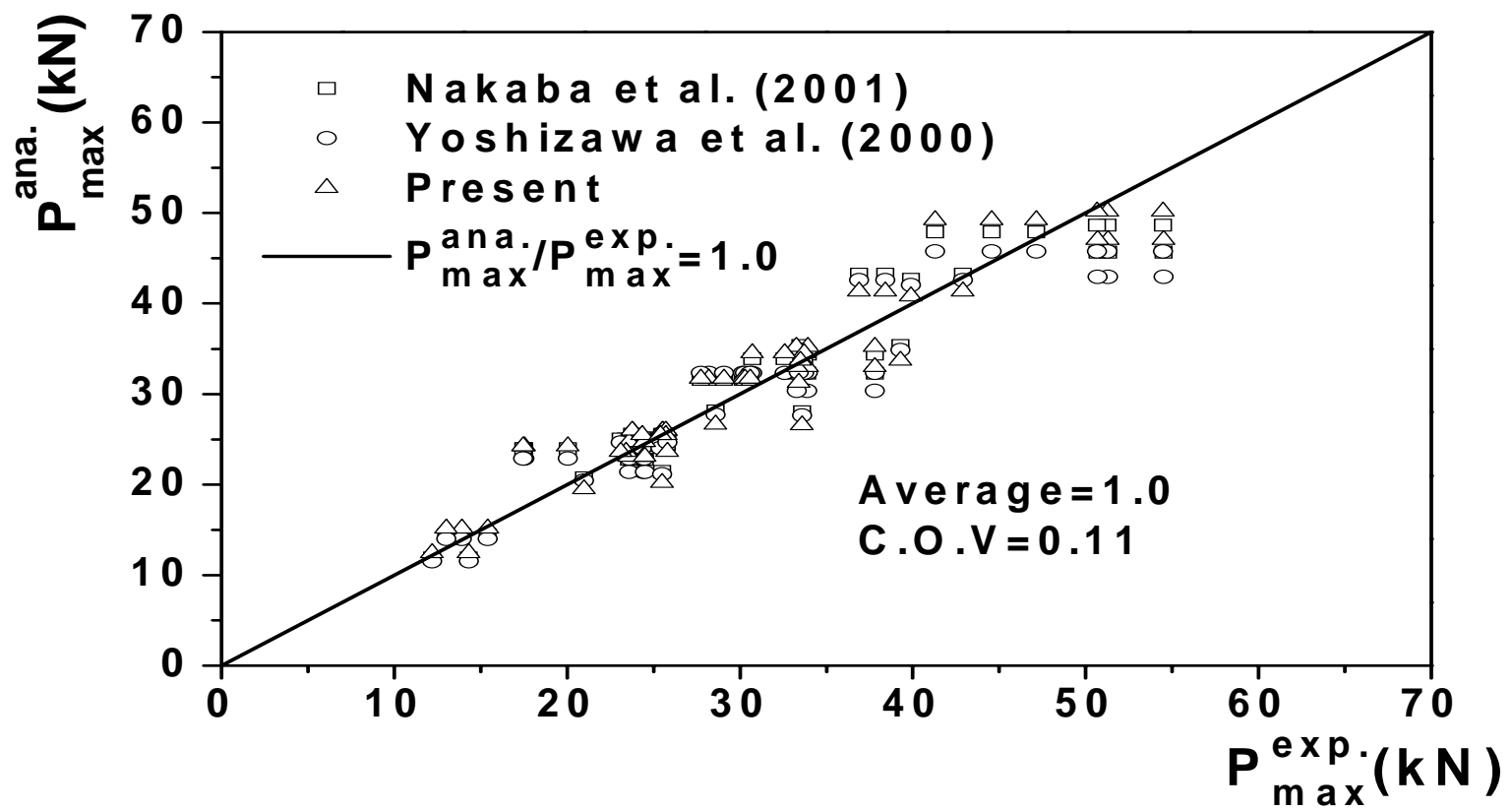


Fig. 15 (17.78cm wide, suggest reduction to $50 \%)$

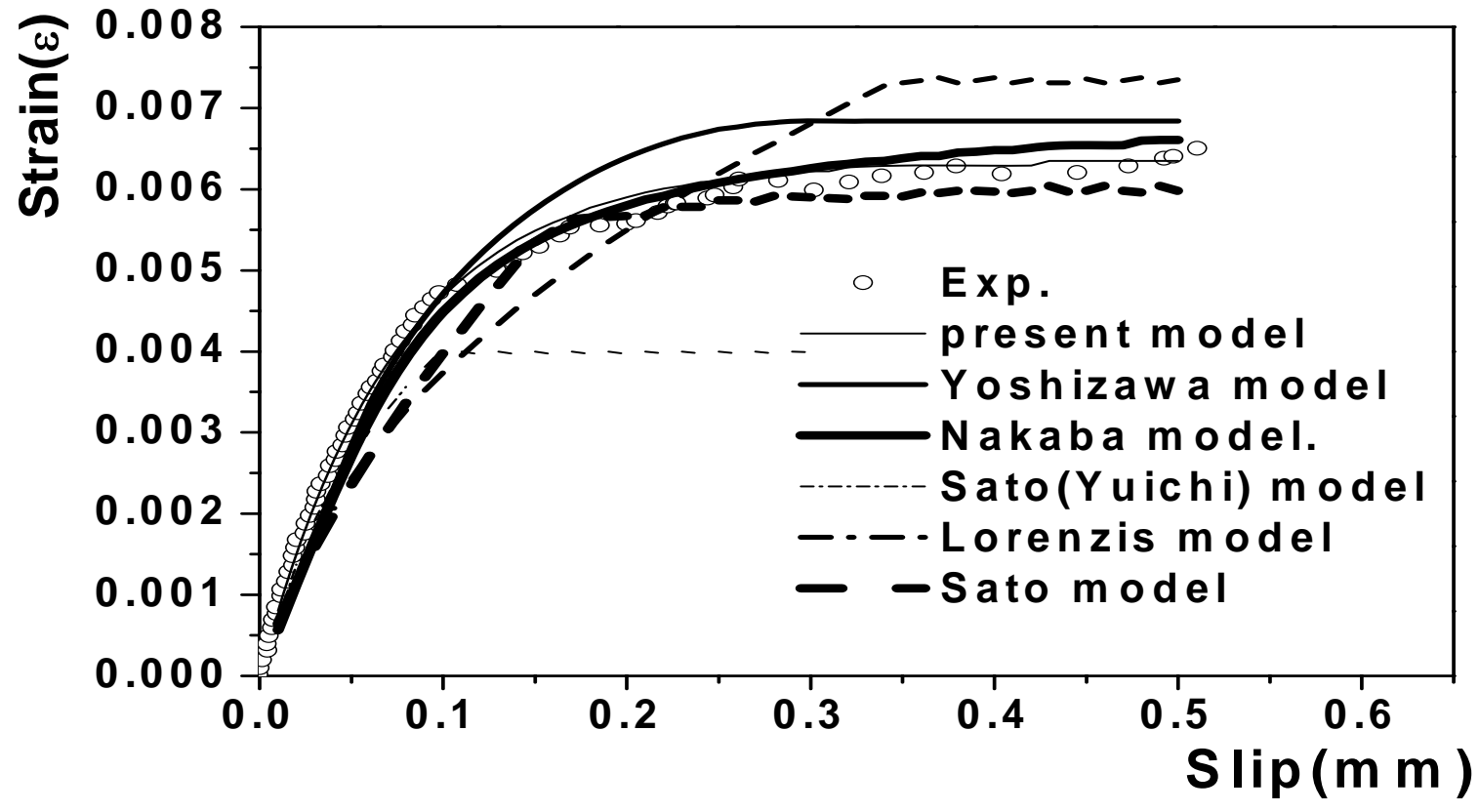




\section{Figure Captions:}

Fig. 1 Previous bond stress-slip relationships of FRP sheet-concrete interfaces

Fig. 2 Pullout test setup

Fig. 3 Tensile stress-strain relations of adhesives

Fig. 4 Microscopic observation of FRP sheets after pullout test (CR3L1)

Fig. 5 Single lap pullout test

Fig. 6 Strain distribution of FRP sheets along bond interface (CR1L1)

Fig. 7 Calculated local bond stress-slip relationships at different locations from loaded end (CR1L1)

Fig. 8 Experimental and regressed strain-slip curves at loaded ends
(a) CFRP, Stiffness: $25.3 \mathrm{kN} / \mathrm{mm}$
(b) CFRP, Stiffness: $50.6 \mathrm{kN} / \mathrm{mm}$
(c) CFRP, Stiffness: $75.9 \mathrm{kN} / \mathrm{mm}$
(d) AFRP, Stiffness: 18.6 73.6 kN/mm
(e) GFRP, Stiffness: 8.7 43.7 kN/mm

Fig. 9 Comparison between analytical and experimental maximum pullout loads

Fig. 10 Experimentally found bond stress-slip relationships
(a) Adhesive FR-E3P
(b) Adhesive SX-325
(c) Adhesive $\mathrm{CN}-100$

Fig. 11 Effects of various parameters on interfacial fracture energy
(a) Concrete strength
(b) FRP stiffness
(c) Adhesive

Fig. 12 Effects of various parameters on $B$
(a) FRP stiffness
(b) Adhesive

Fig. 13 Proposed bond stress-slip relationships

(a) with different FRP stiffness 
(b) with different adhesives

Fig. 14 Comparisons of predicted and experimental ultimate loads of interfaces

Fig. 15 Predicted strain-slip relationships at loading point by different models 


\section{Tables:}

Table 1 Mechanical Properties of FRP Materials

\begin{tabular}{lllllll}
\hline Fiber & Type & $\rho$ & $f_{t}$ & $E_{f}$ & $t_{f}$ & $\varepsilon_{u}$ \\
& & $\left(\mathrm{~g} / \mathrm{m}^{3}\right)$ & $(\mathrm{MPa})$ & $(\mathrm{GPa})$ & $(\mathrm{mm})$ & $(\%)$ \\
\hline Carbon & FTS-C1-20 & 200 & 3550 & 230 & 0.11 & 1.5 \\
\hline Aramid & AT-90 & 530 & 3030 & 84 & 0.38 & 2.4 \\
\hline Glass & FTS-GE-30 & 300 & 1500 & 74 & 0.12 & 2.1 \\
\hline Note: $\rho$ = fiber density; $f_{t}=$ tensile strength; $E_{f}=$ elastic modulus; $t_{f}=$ thickness; \\
$\varepsilon_{u}=$ fiber fracturing strain; FTS-C1-20 and FTS-GE-30 sheets were offered by \\
Nippon Steel Composite Co. Ltd; AT-90 was offered by Nippon Aramid Co. Ltd.
\end{tabular}


Table 2 Material Properties of Adhesives

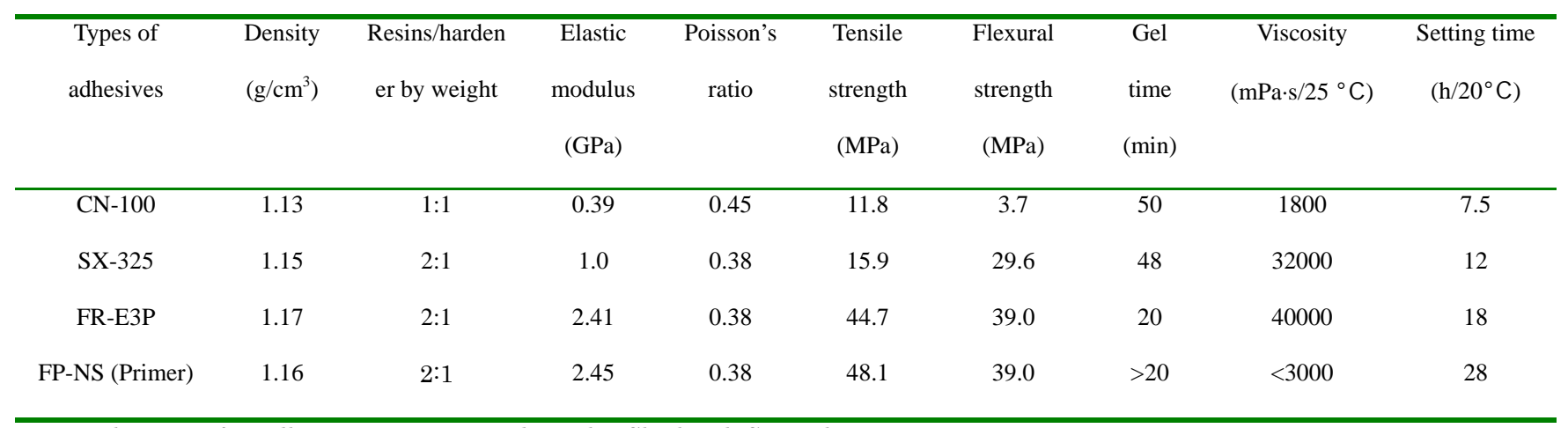

Note: The tests for adhesives were carried out by Sho-bond Co. Ltd., Japan. FR-E3P and FP-NS were offered by Nippon Steel Composite Co. Ltd; SX-325 was offered by Nippon Toho Earth-Tech. Co. Ltd; and CN-100 was offered by Nippon Toho Resin Chemical Co. Ltd. 
Table 3 Details of Specimens and Pullout Bond Test Results

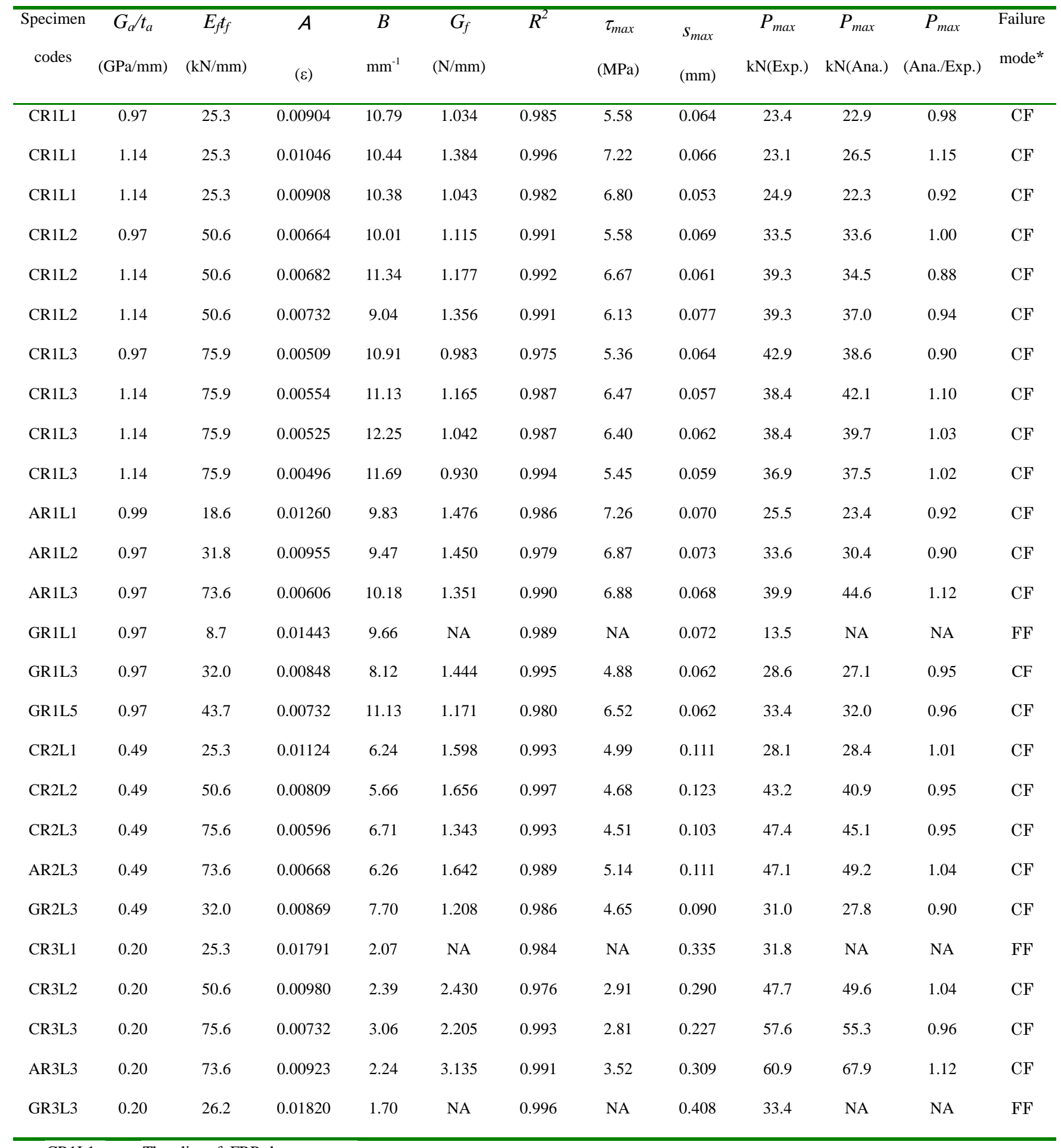

CR1L1 -The plies of FRP sheets

Adhesive type; 1,2 and 3 means FR-E3P, SX-325 and CN-100 respectively

C: CFRP; A: AFRP; G:GFRP 2: CF-concrete failure; 3: FF- FRP fracture; 
Note: $G_{a}$ : Shear modulus of adhesive; $t_{a}$ : thickness of adhesive layer; $E_{f}$ : Elastic modulus of FRP; $t_{f}$ : thickness of FRP; $A, B$ : two regressing parameters used for the relations between the strain of FRP sheet and slip at loaded end of bond area; $R^{2}$ : regressing correlative factor; $\tau_{\max }$ : the maximum bond stress; $s_{\max }$ slip corresponding to the maximum bond stress; NA: the data is not processed because the failure is caused not by the peeling but by the fracture of FRP sheets. 